\title{
种植密度对贵州春玉米茎秆抗倒伏性能及籽粒产量的影响
}

\author{
郑迎霞 $^{1}$ 陈 杜 $^{1}$ 魏鹏程 $^{1}$ 卢 平 $^{2}$ 杨锦越 $^{3}$ 罗上轲 $^{4}$ 叶开梅 $^{1}$ \\ 宋 碧 1 ,* \\ ${ }^{1}$ 贵州大学农学院, 贵州贵阳 $550025 ;^{2}$ 安顺市农业科学研究院, 贵州安顺 $561000 ;^{3}$ 贵州省农业科学院旱粮研究所, 贵州贵阳 \\ $550006 ;{ }^{4}$ 余庆县农业农村局, 贵州余庆 564400
}

摘 要: 为了明确密植条件下春玉米茎秆特性和产量的变化及其相互关系, 为贵州春玉米密植高产提供理论依据和 实践指导。以贵州广泛种植的玉米品种先玉 1171 和新中玉 801 为材料, 设置 3.0、4.5、6.0、7.5、9.0 和 10.5 万株 $\mathrm{hm}^{-2}$ 6 个密度, 于 2018-2019 年开展田间试验, 研究种植密度对春玉米茎秆形态特征和力学特性、空秆率、倒伏率和产 量的影响。结果表明: (1) 春玉米株高和穗位高随密度增加先增高后降低; 增密后第 3 节长增幅最大, 第 3 节单位茎 长干重、穿刺强度和抗折力, 第 7 节茎粗、干重和横截面积下降幅度最大; 密度对茎秆横截面扁率影响不显著。品种 之间比较, 先玉 1171 节间长, 第 3、5 节的节间干重和第 3 节穿刺强度显著高于新中玉 801 , 第 7 节干重、节间粗、 单位茎长干重、节间横截面积、横截面扁率和抗折力显著低于新中玉 801 。(2) 倒伏率和空秆率随密度增加而增大, 增 密后先玉 1171 倒伏率显著高于新中玉 801 , 空秆率显著低于新中玉 801 。(3) 产量随密度增加先增加后降低, 先玉 1171 和新中玉 801 分别在 9.3 万株 $\mathrm{hm}^{-2}$ 和 8.6 万株 $\mathrm{hm}^{-2}$ 时产量最高。增密后先玉 1171 比新中玉 801 增产 $10.28 \%$, 有 效穗数和穗粒数更高。(4) 相关和多元回归分析表明, 株高、穗位高与倒伏率显著正相关, 节间粗和单位茎长干物质 对玉米茎秆抗折力的正向影响显著。产量与茎秆性状密切相关, 株高对产量的正向影响最大。可见, 不同春玉米茎秆 抗倒伏性能和籽粒产量对密度的响应有差异, 新中玉 801 增密后茎秆节间短而粗, 单位茎长干重较大, 抗倒伏能力较 强。而先玉 1171 由于在高密度下空秆率比新中玉 801 低, 有较高的有效穗数和穗粒数, 因此高密度下产量更高。综 合考虑茎秆性状和产量, 先玉 1171 和新中玉 801 在贵州适宜密度分别为 9.0 万株 $\mathrm{hm}^{-2}$ 和 8.5 万株 $\mathrm{hm}^{-2}$ 。

关键词: 春玉米; 种植密度; 茎秆性状; 抗倒伏性能; 籽粒产量

\section{Effects of planting density on lodging resistance and grain yield of spring maize stalks in Guizhou province}

ZHENG Ying-Xia ${ }^{1}$, CHEN Du ${ }^{1}$, WEI Peng-Cheng ${ }^{1}$, LU Ping ${ }^{2}$, YANG Jin-Yue ${ }^{3}$, LUO Shang-Ke ${ }^{4}$, YE

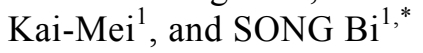

${ }^{1}$ College of Agriculture, Guizhou University, Guiyang 550025, Guizhou, China; ${ }^{2}$ Anshun Academy of Agricultural Sciences, Anshun 561000, Guizhou, China; ${ }^{3}$ Dry Food Research Institute, Guizhou Academy of Agricultural Sciences, Guiyang 550006, Guizhou, China; ${ }^{4}$ Yuqing County Agriculture and Rural Bureau, Yuqing 564400, Guizhou, China

Abstract: The objective of this study was to clarify the changes of spring maize stalk characteristics and yield and their relation-

本研究由国家重点研发计划项目 (2016YFD0300307), 国家公益性行业(农业)科研专项(201503127), 贵州省特色粮油作物栽培与生理 生态研究科技创新人才团队 (黔科合平台人才项目 [2019]5613 号), 贵州省高层次创新型人才“百”层次人才项目(黔科合平台人才 [2018]5632 号)和贵州省生物学一流学科建设项目(GNYL[2017]009)资助。

This study was supported by the National Key Research and Development Program of China (2016YFD0300307), the Special Fund for Agro-scientific Research in the Public Interest (201503127), the Guizhou Province Characteristic Grain and Oil Crops Cultivation and Physiological and Ecological Research Technological Innovation Talent Team (Qiankehe Platform Talent [2019]5613), the Guizhou Province High-level Innovative Talents "Hundred" Level Talent Project (Qiankehe Platform Talent [2018]5632), and the Guizhou Province Biology First-class Discipline Construction Project (GNYL[2017]009).

“通信作者(Corresponding author): 宋碧, E-mail: sb6264@126.com

第一作者联系方式: E-mail: 1534570966@qq.com

Received (收稿日期): 2020-07-13; Accepted (接受日期): 2020-10-14; Published online (网络出版日期): 2020-10-29.

URL: https://kns.cnki.net/kcms/detail/11.1809.S.20201029.1413.002.html 
ship under the dense planting conditions, and it provides theoretical basis and practical guidance for high yield of spring maize dense planting in Guizhou province. The field experiments were carried out to study the effect of planting density on spring maize stalk morphology and mechanical properties, empty stalk rate, lodging rate and grain yield using Guizhou's widely planted maize variety Xianyu 1171 and Xinzhongyu 801 with six density $3 \times 10^{4}, 4.5 \times 10^{4}, 6.0 \times 10^{4}, 7.5 \times 10^{4}, 9.0 \times 10^{4}, 10.5 \times 10^{4}$ plants hm ${ }^{-2}$ from 2018 to 2019. The results were as follows: (1) Plant height and ear height of spring maize increased first and then decreased with the increase in density; the third node length increased the most after densification, the third node's dry weight per stem length, puncture strength and flexural strength, the seventh nodal thickness, dry weight and cross-sectional area decreased the most; the density had no significant effect on the flatness of the cross-sectional area of the stem. Compared with the varieties, Xianyu 1171 internode length, the 3rd and 5th internode dry weight and the 3rd node puncture strength were significantly higher than Xinzhongyu 801. The 7th node dry weight, internode thickness, dry weight per stem length, the cross-sectional area, cross-sectional flatness and flexural strength of internodes were significantly lower than that of Xinzhongyu 801. (2) Lodging rate and empty shot rate increased with the increase in density. After densification, the lodging rate of Xianyu 1171 was significantly higher than that of Xinzhongyu 801, and the rate of empty shot was significantly lower than that of Xinzhongyu 801. (3) The yield increased first and then decreased with the increase in density. Xianyu 1171 and Xinzhongyu 801 had the highest yields at 93,000 plants $\mathrm{hm}^{-2}$ and 86,000 plants $\mathrm{hm}^{-2}$, respectively. After densification, the yield of Xianyu 1171 was higher $10.28 \%$ than that of Xinzhongyu 801, and the number of effective panicles and grains per panicle were higher. (4) Correlation and multiple regression analysis showed that plant height, ear height and lodging rate were significantly positively correlated, and internode thickness and dry matter per stalk length had a significant positive effect on corn stalk bending resistance. The yield was closely related to stalk traits, and plant height had the greatest positive effect on yield. It can be seen that the lodging resistance and grain yield of different spring maize stalks were different in response to density. After the densification of Xinzhongyu 801, the internodes of the stalks were short and thick, the dry weight per stalk length was larger, and the lodging resistance ability was stronger. Because Xianyu 1171 had a lower empty stem rate than Xinzhongyu 801 under high density, it had a higher effective ear number and grain number per ear, the yield was higher under high density. Considering the culm traits and yield, the suitable density of Xianyu 1171 and Xinzhongyu 801 in Guizhou were 90,000 plants hm ${ }^{-2}$ and 85,000 plants hm ${ }^{-2}$, respectively.

Keywords: spring maize; planting density; stalk trait; lodging resistance; grain yield

玉米是我国第一大粮食作物，也是西南区重要 的粮食作物。合理密植充分利用自然资源是实现西南 玉米高产高效栽培的必由之路 ${ }^{[1]}$ 。贵州作为西南重要 的玉米主产区，玉米种植密度偏低，自然资源利用不 足, 成为制约其玉米产业发展的主要问题 ${ }^{[2-3]}$ 。增密能 够增加收获穗数, 使玉米籽粒产量得以提高, 但是, 当种植密度增加到一定程度后会影响玉米的茎秆性 状和产量 ${ }^{[4-6]}$ 。因此, 研究种植密度对春玉米茎秆抗倒 伏性能和籽粒产量的影响, 对指导贵州春玉米实现 密植高产高效栽培具有重要的理论价值和实践意义。

种植密度通过影响玉米品种的株高、穗位高、 节间长度、茎粗、穿刺强度和抗折力等茎秆性状来 影响其抗倒伏特性 ${ }^{[7-8]}$ 。增密使玉米株高和穗位高增 加 $^{[9]}$, 穗下茎节增长、变细, 茎粗系数和茎节干物质 积累量下降, 导致玉米茎秆中干物质积累和分配发 生变化, 茎秆发育质量变差, 倒伏率增加 ${ }^{[10-11]}$ 。同时, 密度也显著影响玉米茎秆力学特性, 随着密度的增 加, 穿刺强度和抗折力显著降低, 倒伏风险增加 ${ }^{[9,12-13]}$ 。 在高密度条件下, 玉米株高和穗位高较矮, 基部节 间短; 节间粗大的品种, 茎秆穿刺强度和抗折力下 降幅度小, 抗倒伏能力强 ${ }^{[14-16]}$ 。

玉米籽粒产量与种植密度在一定范围内呈显著 正相关, 随着种植密度的增加, 有效穗数显著增加,
穗粒数和百粒重显著降低 ${ }^{[17]}$ 。但当密度过大时, 植 株个体发育不良, 导致空秆增加, 倒伏加重, 有效 穗数增幅降低, 从而导致籽粒产量下降 ${ }^{[18]}$ 。此外, 不 同生态环境下，玉米品种对密度的反应不同，其植 株茎秆发育和籽粒产量存在差异 ${ }^{[2,6]}$ 。综上, 前人对 种植密度影响玉米茎秆抗倒特性和产量的研究已有 报道, 但西南玉米区立体生态气候明显, 区域内气 候复杂多变, 针对贵州春玉米品种抗倒伏性能和产 量对密度的响应及其关系的研究鲜见报道。本文通 过 2 年田间试验, 研究密度对贵州春玉米茎秆形态 特征、力学特性及产量的影响, 探讨密度、茎秆抗 倒伏性能及产量之间的关系, 为贵州春玉米密植高 产栽培提供理论依据和实践参考。

\section{1 材料与方法}

\section{1 试验地概况}

2018-2019 年, 试验在贵州省黔中地区安顺市 普定县 $\left(26^{\circ} 32^{\prime} \mathrm{N}, 105^{\circ} 75^{\prime} \mathrm{E}\right)$ 进行, 该区域属于亚热带 季风湿润气候, 年平均日照时数 $1164.9 \mathrm{~h}$, 无霜期 $301 \mathrm{~d}$, 玉米生育期内降雨量和气温见图 1。试验地 为黄壤, $\mathrm{pH} 6.01$, 含有机质 $15.96 \mathrm{~g} \mathrm{~kg}^{-1}$ 、碱解氮 $36.78 \mathrm{mg} \mathrm{kg}^{-1}$ 、全钾 $17.53 \mathrm{~g} \mathrm{~kg}^{-1}$ 、速效磷 $14.33 \mathrm{mg} \mathrm{kg}^{-1}$ 、 速效钾 $136.29 \mathrm{mg} \mathrm{kg}^{-1}$ 。 

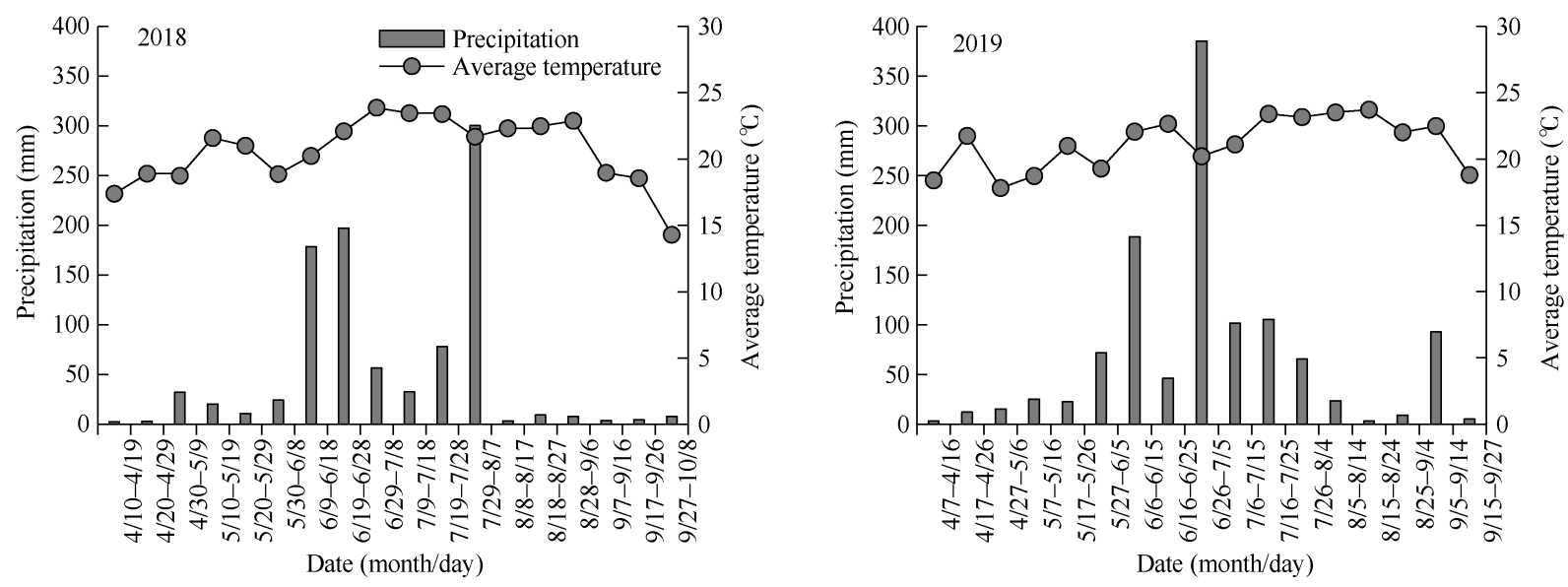

图 1 玉米生育期内气温和降雨量

Fig. 1 Average temperature and rainfall during whole growth stages in maize

\section{2 试验设计}

采用二因素裂区设计, 品种为主区, 选用先玉 1171 (紧凑型)和新中玉 801 (平展型) 2 个品种。密度 为副区, 设置 6 个水平, 分别为 $3.0(\mathrm{D} 1) 、 4.5(\mathrm{D} 2)$ 、 6.0 (D3)、 7.5 (D4)、9.0 (D5)和 10.5 (D6)万株 $\mathrm{hm}^{-2}$, 共 12 个处理, 3 次重复。采用宽窄行种植, 宽行距 $0.8 \mathrm{~m}$, 窄行距 $0.4 \mathrm{~m}$, 株距依密度而定, 小区面积 $19.8 \mathrm{~m}^{2}(3.6 \mathrm{~m} \times 7.5 \mathrm{~m})$ 。基肥施用复合肥 $\left(\mathrm{N}: \mathrm{P}_{2} \mathrm{O}_{5}\right.$ ： $\left.\mathrm{K}_{2} \mathrm{O}=15 ： 15 ： 15\right) 600 \mathrm{~kg} \mathrm{hm}^{-2}$, 在拔节期和大喇叭 口期, 尿素追肥, 用量分别为 $150 \mathrm{~kg} \mathrm{hm}^{-2}$ 和 $225 \mathrm{~kg}$ $\mathrm{hm}^{-2}$ 。其他栽培管理措施同当地大面积生产。

\section{3 测定项目与方法}

\subsection{1 茎秆形态 玉米吐丝后 $30 \mathrm{~d}$ ，每小区选择} 代表性植株 10 株, 测量株高、穗位高, 剥去茎鞘、 叶, 用直尺和游标卡尺, 分别测定玉米茎秆地上第 $3 、 5 、 7$ 节间长度、节间中部长轴直径和短轴直径, 并 称量鲜重。然后置于烘箱 $105^{\circ} \mathrm{C}$ 杀青 $30 \mathrm{~min}$ 后, 于 $80^{\circ} \mathrm{C}$ 烘干至恒重, 称量干重。计算: (1)穗位系数 $=$ 穗位高 / 株高; (2) 节间横截面面积 $\left(\mathrm{cm}^{2}\right)=$ $1 / 4 \times \pi \times \mathrm{L} 1 \times \mathrm{L} 2$, 其中 $\mathrm{L} 1$ 为长轴直径, L 2 为短轴直径; (3)横截面扁率 $=(\mathrm{L} 1-\mathrm{L} 2) / \mathrm{L} 1$; (4) 单位茎长干重 $(\mathrm{g}$ $\left.\mathrm{cm}^{-1}\right)=$ 节间干重/节间长度 ${ }^{[19]}$ 。

1.3.2 茎秆机械强度 玉米吐丝后 $30 \mathrm{~d}$, 每小区 选择代表性植株 10 株, 剥去茎鞘和叶, 采用 YYD-1 型茎秆强度测定仪(浙江托普仪器有限公司生产)测 定玉米茎秆地上第 3、5、7 节节间中部的穿刺强度 和抗折力。

1.3.3 倒伏率和空秆率在成熟期, 调查田间的 倒伏和空秆情况, 测定倒伏率和空秆率。倒伏率 $(\%)=$ 小区倒伏株数 $/$ 小区总株数 $\times 100$; 空秆率 $(\%)=$ 小区
空秆株数 $/$ 小区总株数 $\times 100$ 。

1.3.4 产量 成熟后, 分小区实收测产, 根据小 区产量计算出每公顷产量。每小区选取 20 个具有代 表性果穗进行室内考种。

\section{4 数据处理}

利用 Microsoft Excel 2010 进行数据整理和作图, 用 DPSv7.05 软件进行方差分析, 其中, 采用 LSD 法 检验处理间的差异显著性。

\section{2 结果与分析}

2.1 种植密度对春玉米株高、穗位高和穗位系数 的影响

由表 1 可知, 密度极显著影响春玉米株高、穗 位高和穗位系数。随着密度的增加, 2 个品种的株高 和穗位高呈先增加后减小的趋势, 在 D5 密度下最 高; 穗位系数则表现为先玉 1171 随密度增加先升高 后降低, 新中玉 801 随密度增加而升高; 不同密度 下先玉 1171 株高变异系数较小, 穗位系数变异程度 较大。2 年株高和穗位高均值先玉 $1171(298.1 \mathrm{~cm}$, $93.5 \mathrm{~cm})$ 极显著高于新中玉 $801(232.6 \mathrm{~cm}, 85.1 \mathrm{~cm})$, 穗位系数(0.31)极显著低于新中玉 801 (0.37)。2 2018 年 2 个品种平均株高和穗位高 $(280.7 \mathrm{~cm}, 95.3 \mathrm{~cm})$ 极 显著高于 2019 年 $(250.0 \mathrm{~cm}, 83.2 \mathrm{~cm})$, 穗位系数差异 不显著。

\section{2 种植密度对春玉米茎秆形态特征的影响}

2.2.1节间长度和茎粗 由表 2 可知, 第 $3 、 5 、 7$ 节的节间长度随着密度增大而增长, 茎粗随密度的 增大逐渐变细。与 D1 密度相比, D2 D6 密度下, 节 间长度分别增加了 $3.47 \% \sim 23.17 \% 、 6.76 \% \sim 19.42 \%$ 和 $5.80 \% \sim 13.21 \%$; 茎粗分别下降 $3.20 \% \sim 25.40 \%$ 、 
表 1 种植密度对不同春玉米株高、穗位高、穗位系数的影响

Table 1 Effects of planting density on plant height, ear height, and ear position coefficient of different spring maize

\begin{tabular}{|c|c|c|c|c|c|c|c|}
\hline \multirow[b]{2}{*}{$\begin{array}{c}\text { 品种 } \\
\text { Varieties }\end{array}$} & \multirow[b]{2}{*}{$\begin{array}{c}\text { 密度 } \\
\text { Density }\end{array}$} & \multicolumn{3}{|c|}{2018} & \multicolumn{3}{|c|}{2019} \\
\hline & & $\begin{array}{c}\text { 株高 } \\
\text { Plant height } \\
(\mathrm{cm})\end{array}$ & $\begin{array}{c}\text { 穗位高 } \\
\text { Ear height } \\
(\mathrm{cm})\end{array}$ & $\begin{array}{l}\text { 穗位系数 } \\
\text { Ear position } \\
\text { coefficient } \\
\end{array}$ & $\begin{array}{c}\text { 株高 } \\
\text { Plant height } \\
(\mathrm{cm})\end{array}$ & $\begin{array}{c}\text { 穗位高 } \\
\text { Ear height } \\
(\mathrm{cm})\end{array}$ & $\begin{array}{c}\text { 穗位系数 } \\
\text { Ear position } \\
\text { coefficient }\end{array}$ \\
\hline \multirow{6}{*}{$\begin{array}{l}\text { 先玉 } 1171 \\
\text { Xianyu } 1171\end{array}$} & D1 & $299.6 \mathrm{c}$ & $89.2 \mathrm{~d}$ & $0.30 \mathrm{c}$ & $256.6 \mathrm{~d}$ & $71.2 \mathrm{~d}$ & $0.28 \mathrm{~b}$ \\
\hline & D2 & $318.2 \mathrm{~b}$ & $97.5 \mathrm{~cd}$ & $0.31 \mathrm{bc}$ & $271.7 \mathrm{c}$ & $76.4 \mathrm{~cd}$ & $0.28 \mathrm{~b}$ \\
\hline & D3 & $324.2 \mathrm{ab}$ & $102.4 \mathrm{bc}$ & $0.32 \mathrm{bc}$ & $277.7 \mathrm{bc}$ & $82.9 \mathrm{abc}$ & $0.30 \mathrm{ab}$ \\
\hline & D4 & $332.0 \mathrm{a}$ & $109.1 \mathrm{ab}$ & $0.33 \mathrm{a}$ & $289.8 \mathrm{a}$ & $89.7 \mathrm{a}$ & $0.31 \mathrm{a}$ \\
\hline & D5 & $331.3 \mathrm{a}$ & $118.2 \mathrm{a}$ & $0.36 \mathrm{a}$ & $279.7 \mathrm{~b}$ & $89.8 \mathrm{a}$ & $0.32 \mathrm{a}$ \\
\hline & D6 & $320.0 \mathrm{ab}$ & $109.7 \mathrm{ab}$ & $0.34 \mathrm{a}$ & $276.9 \mathrm{bc}$ & $85.8 \mathrm{ab}$ & $0.31 \mathrm{a}$ \\
\hline 平均值 Mean & & 320.9 & 104.4 & 0.32 & 275.4 & 82.7 & 0.3 \\
\hline 变异系数 CV (\%) & & 4.52 & 12.30 & 9.07 & 4.57 & 10.21 & 7.85 \\
\hline 新中玉 801 & D1 & $234.1 \mathrm{bc}$ & $77.6 \mathrm{~b}$ & $0.33 \mathrm{c}$ & $212.5 \mathrm{~d}$ & $73.7 \mathrm{~b}$ & $0.35 \mathrm{c}$ \\
\hline \multirow[t]{5}{*}{ Xinzhongyu 801} & D2 & $233.0 \mathrm{c}$ & $78.1 \mathrm{~b}$ & $0.33 \mathrm{bc}$ & $217.5 \mathrm{~cd}$ & $77.1 \mathrm{~b}$ & $0.35 \mathrm{bc}$ \\
\hline & D3 & $246.0 \mathrm{ab}$ & $88.6 \mathrm{a}$ & $0.36 \mathrm{ab}$ & $230.2 \mathrm{ab}$ & $88.5 \mathrm{a}$ & $0.38 \mathrm{a}$ \\
\hline & D4 & $239.2 \mathrm{abc}$ & $88.1 \mathrm{a}$ & $0.37 \mathrm{a}$ & $223.6 \mathrm{bc}$ & 83.9 a & $0.37 \mathrm{a}$ \\
\hline & D5 & $248.9 \mathrm{a}$ & $93.1 \mathrm{a}$ & $0.37 \mathrm{a}$ & $234.3 \mathrm{a}$ & $90.3 \mathrm{a}$ & $0.38 \mathrm{a}$ \\
\hline & D6 & $242.5 \mathrm{abc}$ & $92.5 \mathrm{a}$ & $0.38 \mathrm{a}$ & $230.0 \mathrm{ab}$ & $89.5 \mathrm{a}$ & $0.39 \mathrm{a}$ \\
\hline 平均值 Mean & & 240.6 & 86.3 & 0.36 & 224.7 & 83.8 & 0.37 \\
\hline 变异系数 CV (\%) & & 5.32 & 11.26 & 7.21 & 5.46 & 11.12 & 5.97 \\
\hline 变异来源 & \multicolumn{2}{|c|}{ 品种 Varieties (V) } & \multicolumn{2}{|r|}{ ** } & $* *$ & \multicolumn{2}{|c|}{$* *$} \\
\hline \multicolumn{3}{|c|}{ Source of variation 密度 Density (D) } & \multicolumn{2}{|r|}{ ** } & ** & \multicolumn{2}{|r|}{$* *$} \\
\hline \multicolumn{3}{|c|}{ 年份 Year (Y) } & \multicolumn{2}{|r|}{$* *$} & ** & \multicolumn{2}{|c|}{ ns } \\
\hline \multicolumn{3}{|c|}{ 品种×密度 $(\mathrm{V} \times \mathrm{D})$} & \multicolumn{2}{|r|}{ ns } & $\mathrm{ns}$ & \multicolumn{2}{|r|}{ ns } \\
\hline \multicolumn{3}{|c|}{ 品种 $\times$ 年份 $(V \times D)$} & \multicolumn{2}{|r|}{$* *$} & ** & \multicolumn{2}{|r|}{$* *$} \\
\hline & \multicolumn{2}{|c|}{ 密度×年份 $(D \times Y)$} & \multicolumn{2}{|r|}{ ns } & $\mathrm{ns}$ & \multicolumn{2}{|r|}{ ns } \\
\hline
\end{tabular}

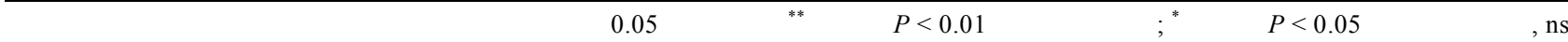
表示差异不显著。D1、D2、D3、D4、D5 和 D6 分别代表种植密度 $3.0 \times 10^{4} 、 4.5 \times 10^{4} 、 6.0 \times 10^{4} 、 7.5 \times 10^{4} 、 9.0 \times 10^{4}$ 和 $10.5 \times 10^{4}$ 株 $\mathrm{hm}^{-2}$ 。 Values within a column followed by different lowercase letters are significantly different at the 0.05 probability level among different treatments. "*, significantly different at $P<0.01$; ", significantly different at $P<0.05$; ns, the difference was not significant. D1, D2, D3, D4, D5, and D6 represent planting densities of $3.0 \times 10^{4}, 4.5 \times 10^{4}, 6.0 \times 10^{4}, 7.5 \times 10^{4}, 9.0 \times 10^{4}$, and $10.5 \times 10^{4}$ plants hm ${ }^{-2}$, respectively.

$3.03 \% \sim 25.98 \%$ 和 $3.33 \% \sim 27.49 \%$ ，密度对春玉米第 3 节节间长度和第 7 节茎粗影响最大。2 年平均节间 长度先玉 1171 极显著高于新中玉 801 ; 茎粗极显著 低于新中玉 801 ; 不同密度下, 先玉 1171 节间长度 变异较小, 茎粗 2018 年先玉 1171 变异系数较小, 2019 年新中玉 801 变异系数较小, 可见先玉 1171 节 间长度对密度的响应较为迟缓, 2 个品种茎粗对密度 的响应受环境影响较大。此外, 2018 年 2 个品种第 5 、 7 节平均节间长度和茎粗极显著高于 2019 年; 第 3 节平均茎粗极显著低于 2019 年, 第 3 节节间长度 2 年差异不显著。品种、密度互作显著或极显著影响
第 3、5、7 茎粗; 品种、年份互作显著或极显著影 响除第 3 节长以外的节间长与粗。表明春玉米茎秆 第 3 节节间长在不同年际间相对稳定。

2.2.2 节间干物质重 由表 3 可知, 春玉米第 3 、 $5 、 7$ 节间干重和单位茎长干重随密度增大逐渐下降, 与 D1 密度相比, D2 D6 密度下, 第 3、5 和 7 节干重 分别下降 $11.05 \% \sim 42.85 \% 、 4.35 \% \sim 42.97 \%$ 和 $8.88 \% \sim 47.87 \%$; 单位茎长干重分别下降了 $17.61 \% \sim 58.16 \% 、 11.87 \% \sim 55.13 \%$ 和 $13.58 \% \sim 53.61 \%$, 密度对第 7 节干重和第 3 节单位茎长干重影响最大。 不同密度下, 节间干重和单位茎长干重 2 年均表现 
表 2 种植密度对不同春玉米玉米茎秆节间长、粗的影响

Table 2 Effects of planting density on internode length and internode stem thickness of different spring maize

\begin{tabular}{|c|c|c|c|c|c|c|c|c|c|c|c|c|c|}
\hline \multirow{3}{*}{$\begin{array}{c}\text { 品种 } \\
\text { Varieties }\end{array}$} & \multirow{3}{*}{$\begin{array}{c}\text { 密度 } \\
\text { Den- } \\
\text { sity }\end{array}$} & \multicolumn{6}{|c|}{2018} & \multicolumn{6}{|c|}{2019} \\
\hline & & \multicolumn{3}{|c|}{$\begin{array}{c}\text { 节间长度 } \\
\text { Internode length }(\mathrm{cm})\end{array}$} & \multicolumn{3}{|c|}{$\begin{array}{c}\text { 节间粗 } \\
\text { Internode stem thickness } \\
(\mathrm{mm}) \\
\end{array}$} & \multicolumn{3}{|c|}{$\begin{array}{c}\text { 节间长度 } \\
\text { Internode length }(\mathrm{cm})\end{array}$} & \multicolumn{3}{|c|}{$\begin{array}{c}\text { 节间粗 } \\
\text { Internode stem thickness } \\
(\mathrm{mm})\end{array}$} \\
\hline & & 3 & 5 & 7 & 3 & 5 & 7 & 3 & 5 & 7 & 3 & 5 & 7 \\
\hline \multirow{6}{*}{$\begin{array}{l}\text { 先玉 } 1171 \\
\text { Xianyu } 1171\end{array}$} & D1 & $13.76 \mathrm{~d}$ & $18.83 \mathrm{a}$ & $18.84 \mathrm{a}$ & $21.50 \mathrm{a}$ & $20.59 \mathrm{a}$ & $18.88 \mathrm{a}$ & $13.09 \mathrm{~b}$ & $17.72 \mathrm{~d}$ & $17.64 \mathrm{~b}$ & $20.47 \mathrm{a}$ & $18.81 \mathrm{a}$ & $15.72 \mathrm{a}$ \\
\hline & D2 & $13.71 \mathrm{~d}$ & $20.03 \mathrm{a}$ & $20.49 \mathrm{a}$ & $21.30 \mathrm{a}$ & $20.17 \mathrm{a}$ & $18.61 \mathrm{a}$ & $13.19 \mathrm{~b}$ & $19.03 \mathrm{~cd}$ & $19.63 \mathrm{a}$ & $20.49 a$ & $18.97 \mathrm{a}$ & $15.30 \mathrm{a}$ \\
\hline & D3 & $14.34 \mathrm{~cd}$ & $20.72 \mathrm{a}$ & $20.39 \mathrm{a}$ & $19.83 \mathrm{~b}$ & $19.11 \mathrm{~b}$ & $17.18 \mathrm{~b}$ & $14.41 \mathrm{~b}$ & $19.87 \mathrm{bc}$ & $19.29 \mathrm{a}$ & $18.89 \mathrm{~b}$ & $17.06 \mathrm{~b}$ & $13.96 \mathrm{~b}$ \\
\hline & D4 & $15.18 \mathrm{bc}$ & $22.28 \mathrm{a}$ & $22.10 \mathrm{a}$ & $18.97 \mathrm{~b}$ & $17.55 \mathrm{c}$ & $16.48 \mathrm{~b}$ & $15.97 \mathrm{a}$ & $20.61 \mathrm{ab}$ & $19.83 \mathrm{a}$ & $17.34 \mathrm{c}$ & $16.00 \mathrm{c}$ & $13.22 \mathrm{bc}$ \\
\hline & D5 & $16.22 \mathrm{ab}$ & $21.70 \mathrm{a}$ & $21.65 \mathrm{a}$ & $17.71 \mathrm{c}$ & $16.74 \mathrm{~cd}$ & d $15.37 \mathrm{c}$ & $16.03 \mathrm{a}$ & $21.98 \mathrm{a}$ & $20.41 \mathrm{a}$ & $16.41 \mathrm{~cd}$ & $15.08 \mathrm{c}$ & $12.39 \mathrm{~cd}$ \\
\hline & D6 & $16.67 \mathrm{a}$ & $21.94 \mathrm{a}$ & $20.40 \mathrm{a}$ & $17.07 \mathrm{c}$ & $16.33 \mathrm{~cd}$ & d $15.28 \mathrm{c}$ & $17.25 \mathrm{a}$ & $22.05 \mathrm{a}$ & $19.27 \mathrm{a}$ & $15.37 d$ & $13.81 \mathrm{~d}$ & $11.29 \mathrm{~d}$ \\
\hline \multicolumn{2}{|l|}{ 平均值 Mean } & 14.98 & 20.92 & 20.65 & 19.4 & 17.98 & 16.94 & 14.99 & 20.21 & 19.35 & 18.10 & 16.62 & 13.65 \\
\hline \multicolumn{2}{|l|}{ 变异系数 CV (\%) } & 11.83 & 8.95 & 8.46 & 10.32 & 10.64 & 10.40 & 17.54 & 11.31 & 7.31 & 12.74 & 13.77 & 16.87 \\
\hline \multirow{6}{*}{$\begin{array}{l}\text { 新中玉 } 801 \\
\text { Xinzhongyu } 801\end{array}$} & D1 & $8.88 \mathrm{~b}$ & $14.21 \mathrm{c}$ & $17.03 \mathrm{~b}$ & $23.95 \mathrm{a}$ & $23.91 \mathrm{a}$ & $22.77 \mathrm{a}$ & $9.23 \mathrm{c}$ & $12.38 \mathrm{c}$ & $14.17 \mathrm{~b}$ & $25.88 \mathrm{a}$ & $23.05 \mathrm{a}$ & $20.17 \mathrm{a}$ \\
\hline & D2 & $9.86 \mathrm{~b}$ & $15.94 \mathrm{bc}$ & $17.65 \mathrm{~b}$ & $22.52 \mathrm{~b}$ & $22.09 \mathrm{~b}$ & $21.11 \mathrm{~b}$ & $9.81 \mathrm{c}$ & $12.72 \mathrm{bc}$ & $14.07 \mathrm{~b}$ & $24.59 \mathrm{ab}$ & $22.1 \mathrm{ab}$ & $19.95 \mathrm{a}$ \\
\hline & D3 & $12.17 \mathrm{a}$ & $22.38 \mathrm{a}$ & $16.86 \mathrm{~b}$ & $20.19 \mathrm{c}$ & $19.81 \mathrm{c}$ & $19.05 \mathrm{c}$ & $11.19 \mathrm{ab}$ & $14.63 \mathrm{a}$ & $15.52 \mathrm{a}$ & $23.47 \mathrm{~b}$ & $20.89 \mathrm{~b}$ & $19.28 \mathrm{a}$ \\
\hline & D4 & $12.89 \mathrm{a}$ & $17.33 \mathrm{bc}$ & $18.33 \mathrm{ab}$ & $18.09 \mathrm{~d}$ & $17.99 \mathrm{~d}$ & $17.81 \mathrm{~d}$ & $10.33 \mathrm{bc}$ & $14.09 \mathrm{ab}$ & $15.69 \mathrm{a}$ & $21.25 \mathrm{c}$ & $19.46 \mathrm{c}$ & $17.27 \mathrm{~b}$ \\
\hline & D5 & $12.87 \mathrm{a}$ & $18.88 \mathrm{ab}$ & $19.48 \mathrm{a}$ & $17.22 \mathrm{e}$ & $16.72 \mathrm{e}$ & $16.17 \mathrm{e}$ & $11.99 \mathrm{a}$ & 15.78 a & $16.44 \mathrm{a}$ & $20.37 \mathrm{c}$ & $18.44 \mathrm{~d}$ & $16.13 \mathrm{~b}$ \\
\hline & D6 & $12.10 \mathrm{a}$ & $18.60 \mathrm{ab}$ & $18.05 \mathrm{ab}$ & $16.62 \mathrm{e}$ & $16.45 \mathrm{e}$ & $14.96 \mathrm{f}$ & $12.49 \mathrm{a}$ & $15.60 \mathrm{a}$ & $16.81 \mathrm{a}$ & $18.66 \mathrm{~d}$ & $16.77 \mathrm{e}$ & $14.71 \mathrm{c}$ \\
\hline \multicolumn{2}{|l|}{ 平均值 Mean } & 11.46 & 17.06 & 17.9 & 19.77 & 19.50 & 18.64 & 10.84 & 14.2 & 15.45 & 22.37 & 20.12 & 17.92 \\
\hline \multicolumn{2}{|l|}{ 变异系数 CV (\%) } & 17.31 & 13.62 & 10.93 & 15.56 & 14.60 & 15.31 & 17.22 & 16.16 & 13.50 & 12.65 & 12.05 & 14.60 \\
\hline 变异来源 & \multicolumn{3}{|c|}{ 品种 Varieties (V) } & \multicolumn{2}{|c|}{ ** } & ** & ** & \multicolumn{3}{|c|}{$* *$} & ** & \multicolumn{2}{|c|}{$* *$} \\
\hline \multirow{5}{*}{$\begin{array}{l}\text { Source of } \\
\text { variation }\end{array}$} & \multicolumn{3}{|c|}{ 密度 Density (D) } & \multicolumn{2}{|c|}{ ** } & ** & ${ }^{* *}$ & \multicolumn{3}{|c|}{${ }^{* *}$} & ${ }^{* *}$ & \multicolumn{2}{|c|}{ ** } \\
\hline & \multicolumn{3}{|c|}{ 年份 Year (Y) } & \multicolumn{2}{|c|}{ ns } & ** & ** & \multicolumn{3}{|c|}{$* *$} & $* *$ & \multicolumn{2}{|c|}{ ** } \\
\hline & \multicolumn{2}{|c|}{$\begin{array}{l}\text { 品种×密度 } \\
(\mathrm{V} \times \mathrm{D})\end{array}$} & \multicolumn{2}{|c|}{$\mathrm{ns}$} & & $\mathrm{ns}$ & ns & \multicolumn{3}{|c|}{ ** } & $*$ & & \\
\hline & $\begin{array}{l}\text { 品种 } \times \\
(\mathrm{V} \times \mathrm{Y})\end{array}$ & 年份 & & is & & ** & * & & ** & & $* *$ & & \\
\hline & $\begin{array}{l}\text { 密度 } \times \\
(D \times Y)\end{array}$ & 平份 & & Is & & $\mathrm{ns}$ & $\mathrm{ns}$ & & ns & & $\mathrm{ns}$ & & \\
\hline
\end{tabular}

处理同表 1。同一列数字后不同小写字母表示不同处理间差异达 0.05 显著水平。 ${ }^{* *}$ 表示在 $P<0.01$ 水平差异显著; ${ }^{*}$ 表示在 $P<0.05$ 水 平差异显著; $\mathrm{ns}$ 表示差异不显著。

Treatments are the same as those given in Table 1. Values within a column followed by different lowercase letters indicate significant differences at the 0.05 probability level among different treatments. ${ }^{* *}$ : significantly different at $P<0.01 ;{ }^{*}$ : significantly different at $P<0.05$; ns: the difference was not significant.

为, 先玉 1171 变异系数小于新中玉 801 , 表明先玉 1171 节间干重和单位茎长干重对密度响应较为迟 钝。 2 年平均节间干重先玉 1171 第 $3 、 5$ 节极显著高 于新中玉 801 , 第 7 节干重和第 3、5、7 节单位茎长
干重显著低于新中玉 801 。2018 年 2 个品种的第 3 节平均节间干重和单位茎长干重显著低于 2019 年; 第 $5 、 7$ 节干重和第 7 节单位茎长干重极显著高于 2019 年。 
表 3 种植度对不同春玉米茎秆节间干物质的影响

Table 3 Effects of planting density on stalk internode dry matter and dry weight per unit stem length of different spring maize

\begin{tabular}{|c|c|c|c|c|c|c|c|c|c|c|c|c|c|}
\hline \multirow{3}{*}{$\begin{array}{c}\text { 品种 } \\
\text { Varieties }\end{array}$} & \multirow{3}{*}{$\begin{array}{c}\text { 密度 } \\
\text { Density }\end{array}$} & \multicolumn{6}{|c|}{2018} & \multicolumn{6}{|c|}{2019} \\
\hline & & \multicolumn{3}{|c|}{$\begin{array}{c}\text { 节间干重 } \\
\text { Internode dry weight } \\
(\mathrm{g})\end{array}$} & \multicolumn{3}{|c|}{$\begin{array}{c}\text { 单位茎长干重 } \\
\text { Dry weight per unit stem } \\
\text { length }\left(\mathrm{g} \mathrm{cm}^{-1}\right) \\
\end{array}$} & \multicolumn{3}{|c|}{$\begin{array}{c}\text { 节间干重 } \\
\text { Internode dry weight } \\
(\mathrm{g}) \\
\end{array}$} & \multicolumn{3}{|c|}{$\begin{array}{c}\text { 单位茎长干重 } \\
\text { Dry weight per unit stem } \\
\text { length }\left(\mathrm{g} \mathrm{cm}^{-1}\right) \\
\end{array}$} \\
\hline & & 3 & 5 & 7 & 3 & 5 & 7 & 3 & 5 & 7 & 3 & 5 & 7 \\
\hline \multirow{6}{*}{$\begin{array}{l}\text { 先玉 } 1171 \\
\text { Xianyu } 1171\end{array}$} & D1 & $9.61 \mathrm{a}$ & $10.17 \mathrm{a}$ & $7.80 \mathrm{a}$ & $0.70 \mathrm{a}$ & $0.54 \mathrm{a}$ & $0.41 \mathrm{a}$ & $9.19 \mathrm{a}$ & $8.00 \mathrm{~b}$ & $4.98 \mathrm{a}$ & $0.71 \mathrm{a}$ & $0.46 \mathrm{ab}$ & $0.40 \mathrm{a}$ \\
\hline & D2 & $8.54 \mathrm{~b}$ & $9.59 \mathrm{a}$ & $7.28 \mathrm{a}$ & $0.62 \mathrm{a}$ & $0.48 \mathrm{~b}$ & $0.35 \mathrm{~b}$ & $9.22 \mathrm{a}$ & $9.21 \mathrm{a}$ & $5.54 \mathrm{a}$ & $0.70 \mathrm{a}$ & $0.49 \mathrm{a}$ & $0.35 \mathrm{a}$ \\
\hline & D3 & $7.40 \mathrm{c}$ & $8.16 \mathrm{~b}$ & $6.15 \mathrm{~b}$ & $0.52 \mathrm{~b}$ & $0.39 \mathrm{c}$ & $0.30 \mathrm{c}$ & $7.94 \mathrm{~b}$ & $7.67 \mathrm{~b}$ & $4.79 \mathrm{ab}$ & $0.56 \mathrm{~b}$ & $0.39 \mathrm{bc}$ & $0.30 \mathrm{~b}$ \\
\hline & D4 & $6.50 \mathrm{~d}$ & $7.56 \mathrm{bc}$ & $5.96 \mathrm{~b}$ & $0.42 \mathrm{c}$ & $0.34 \mathrm{~d}$ & $0.27 \mathrm{c}$ & $7.27 \mathrm{~b}$ & $6.45 \mathrm{c}$ & $4.64 \mathrm{ab}$ & $0.46 \mathrm{c}$ & $0.32 \mathrm{~cd}$ & $0.27 \mathrm{bc}$ \\
\hline & D5 & $6.36 \mathrm{~d}$ & $6.79 \mathrm{~cd}$ & $4.98 \mathrm{c}$ & $0.39 \mathrm{c}$ & $0.32 \mathrm{de}$ & $0.23 \mathrm{~d}$ & $6.35 \mathrm{c}$ & $6.29 \mathrm{c}$ & $3.92 \mathrm{~b}$ & $0.41 \mathrm{c}$ & $0.29 \mathrm{de}$ & $0.23 \mathrm{~cd}$ \\
\hline & D6 & $6.18 \mathrm{~d}$ & $6.16 \mathrm{~d}$ & $4.49 \mathrm{c}$ & $0.37 \mathrm{c}$ & $0.28 \mathrm{e}$ & $0.22 \mathrm{~d}$ & $5.35 \mathrm{~d}$ & $5.13 \mathrm{~d}$ & $2.86 \mathrm{c}$ & $0.31 \mathrm{~d}$ & $0.23 \mathrm{e}$ & $0.19 \mathrm{~d}$ \\
\hline 平均值 Mean & & 7.43 & 8.07 & 6.11 & 0.51 & 0.39 & 0.30 & 7.55 & 7.12 & 4.46 & 0.52 & 0.36 & 0.23 \\
\hline 变异系数 CV (\%) & & 21.57 & 21.90 & 27.66 & 27.30 & 27.56 & 28.72 & 27.03 & 29.50 & 34.76 & 34.59 & 34.47 & 34.50 \\
\hline 新中玉 801 & D1 & $8.05 \mathrm{a}$ & $9.77 \mathrm{a}$ & $9.43 \mathrm{a}$ & $0.97 \mathrm{a}$ & $0.69 \mathrm{a}$ & $0.55 \mathrm{a}$ & $9.29 \mathrm{a}$ & $9.04 \mathrm{a}$ & $7.24 \mathrm{a}$ & $1.04 \mathrm{a}$ & $0.74 \mathrm{a}$ & $0.28 \mathrm{a}$ \\
\hline \multirow[t]{5}{*}{ Xinzhongyu 801} & D2 & $6.74 \mathrm{~b}$ & $9.27 \mathrm{a}$ & $8.05 \mathrm{~b}$ & $0.68 \mathrm{~b}$ & $0.59 \mathrm{~b}$ & $0.46 \mathrm{~b}$ & $7.65 \mathrm{~b}$ & $7.31 \mathrm{~b}$ & $5.96 \mathrm{ab}$ & $0.79 \mathrm{~b}$ & $0.58 \mathrm{~b}$ & $0.28 \mathrm{a}$ \\
\hline & D3 & $5.54 \mathrm{c}$ & $7.14 \mathrm{~b}$ & $6.13 \mathrm{c}$ & $0.45 \mathrm{c}$ & $0.38 \mathrm{c}$ & $0.37 \mathrm{c}$ & $7.17 \mathrm{~b}$ & $7.40 \mathrm{~b}$ & $5.61 \mathrm{bc}$ & $=0.65 \mathrm{c}$ & $0.50 \mathrm{bc}$ & $0.25 \mathrm{a}$ \\
\hline & D4 & $5.31 \mathrm{~cd}$ & $5.83 \mathrm{c}$ & $5.39 \mathrm{~cd}$ & $0.41 \mathrm{~cd}$ & $0.34 \mathrm{~cd}$ & $0.30 \mathrm{~d}$ & $5.80 \mathrm{c}$ & $6.03 \mathrm{c}$ & $4.78 \mathrm{~cd}$ & $0.58 \mathrm{c}$ & $0.44 \mathrm{~cd}$ & $0.23 \mathrm{ab}$ \\
\hline & D5 & $4.71 \mathrm{de}$ & $6.06 \mathrm{c}$ & $5.09 \mathrm{de}$ & $0.36 \mathrm{~d}$ & $0.32 \mathrm{de}$ & $0.26 \mathrm{de}$ & $5.60 \mathrm{c}$ & $5.73 \mathrm{c}$ & $4.41 \mathrm{de}$ & $0.48 \mathrm{~d}$ & $0.37 \mathrm{~d}$ & $0.19 \mathrm{bc}$ \\
\hline & D6 & $4.40 \mathrm{e}$ & $5.42 \mathrm{c}$ & $4.30 \mathrm{e}$ & $0.35 \mathrm{~d}$ & $0.30 \mathrm{e}$ & $0.24 \mathrm{e}$ & $4.73 \mathrm{~d}$ & $4.38 \mathrm{~d}$ & $3.70 \mathrm{e}$ & $0.38 \mathrm{e}$ & $0.28 \mathrm{e}$ & $0.15 \mathrm{c}$ \\
\hline 平均值 Mean & & 5.79 & 7.25 & 6.40 & 0.54 & 0.44 & 0.36 & 6.71 & 6.65 & 5.28 & 0.65 & 0.49 & 0.35 \\
\hline 变异系数 CV (\%) & & 25.87 & 27.74 & 31.86 & 46.27 & 36.72 & 34.60 & 28.67 & 32.94 & 36.77 & 41.67 & 41.15 & 38.79 \\
\hline 变异来源 & \multicolumn{3}{|c|}{ 品种 Varieties (V) } & ** & \multicolumn{2}{|c|}{ ** } & $*$ & \multicolumn{2}{|c|}{$* *$} & \multicolumn{2}{|c|}{ ** } & \multicolumn{2}{|c|}{$* *$} \\
\hline \multirow[t]{5}{*}{ Source of variation } & \multicolumn{2}{|c|}{ 密度 Density (D) } & \multicolumn{2}{|c|}{$* *$} & \multicolumn{2}{|c|}{$* *$} & ** & \multicolumn{2}{|c|}{$* *$} & \multicolumn{2}{|c|}{$* *$} & \multicolumn{2}{|c|}{$* *$} \\
\hline & \multicolumn{2}{|c|}{ 年份 Year (Y) } & \multicolumn{2}{|c|}{$*$} & \multicolumn{2}{|c|}{$* *$} & $* *$ & \multicolumn{2}{|c|}{ ** } & $\mathrm{n}$ & is & \multicolumn{2}{|c|}{ ** } \\
\hline & \multicolumn{2}{|c|}{$\begin{array}{l}\text { 品种 } \times \text { 密度 } \\
(V \times D)\end{array}$} & \multicolumn{2}{|c|}{$\mathrm{ns}$} & & ns & $\mathrm{ns}$ & ** & * & 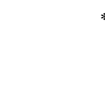 & * & & * \\
\hline & $\begin{array}{l}\text { 品种×年 } \\
(\mathrm{V} \times \mathrm{Y})\end{array}$ & & & ns & & ns & $\mathrm{ns}$ & $\mathrm{ns}$ & is & " & * & & * \\
\hline & $\begin{array}{l}\text { 密度×年 } \\
(\mathrm{D} \times \mathrm{Y})\end{array}$ & & & ns & & ns & $\mathrm{ns}$ & $\mathrm{ns}$ & is & $\mathrm{n}$ & is & & ns \\
\hline
\end{tabular}

处理同表 1 。同一列数字后不同小写字母表示不同处理间差异达 0.05 显著水平。 ${ }^{* *}$ 表示在 $P<0.01$ 水平差异显著; ${ }^{*}$ 表示在 $P<0.05$ 水 平差异显著; $n$ 表示差异不显著。

Treatments are the same as those given in Table 1. Values within a column followed by different lowercase letters are significantly different at the 0.05 probability level among different treatments. ${ }^{* *}$ : significantly different at $P<0.01$; ${ }^{*}$ : significantly different at $P<0.05$; ns: the difference was not significant.

2.2.3 节间横截面积随密度增大, 茎秆横截面 积逐渐降低，且不同处理差异显著(图 2)。与 D1 密 度相比, D2 D6 密度下茎秆横截面积分别下降了 $3.65 \% \sim 45.71 \% 、 4.47 \% \sim 46.92 \%$ 和 $4.57 \% \sim 48.43 \%$, 可 见密度对第 7 节茎秆横截面积影响最大。先玉 1171 第 3、5 和 7 节茎节横截面积均值 $(2.80 、 2.33$ 和 $\left.1.59 \mathrm{~cm}^{2}\right)$ 极显著低于新中玉 $801 \quad(4.39 、 3.51$ 和 $2.77 \mathrm{~cm}^{2}$ )。
2.2.4 节间横截面扁率密度对茎秆节间横截面 扁率有一定影响，但规律不明显(图 2)。先玉 1171 第 3、5、7 节间横截面扁率 $(0.105 、 0.103$ 和 0.100) 显著低于新中玉 $801(0.140 、 0.139$ 和 0.119$)$ 。

\section{3 种植密度对春玉米茎秆力学特性的影响}

由表 4 和图 3 可知, 密度对春玉米茎秆第 $3 、 5$ 、 7 穿刺强度和抗折力影响极显著 $(P<0.01)$ 。随着密度 的增大, 同一节位穿刺强度和抗折力逐渐降低, 与 

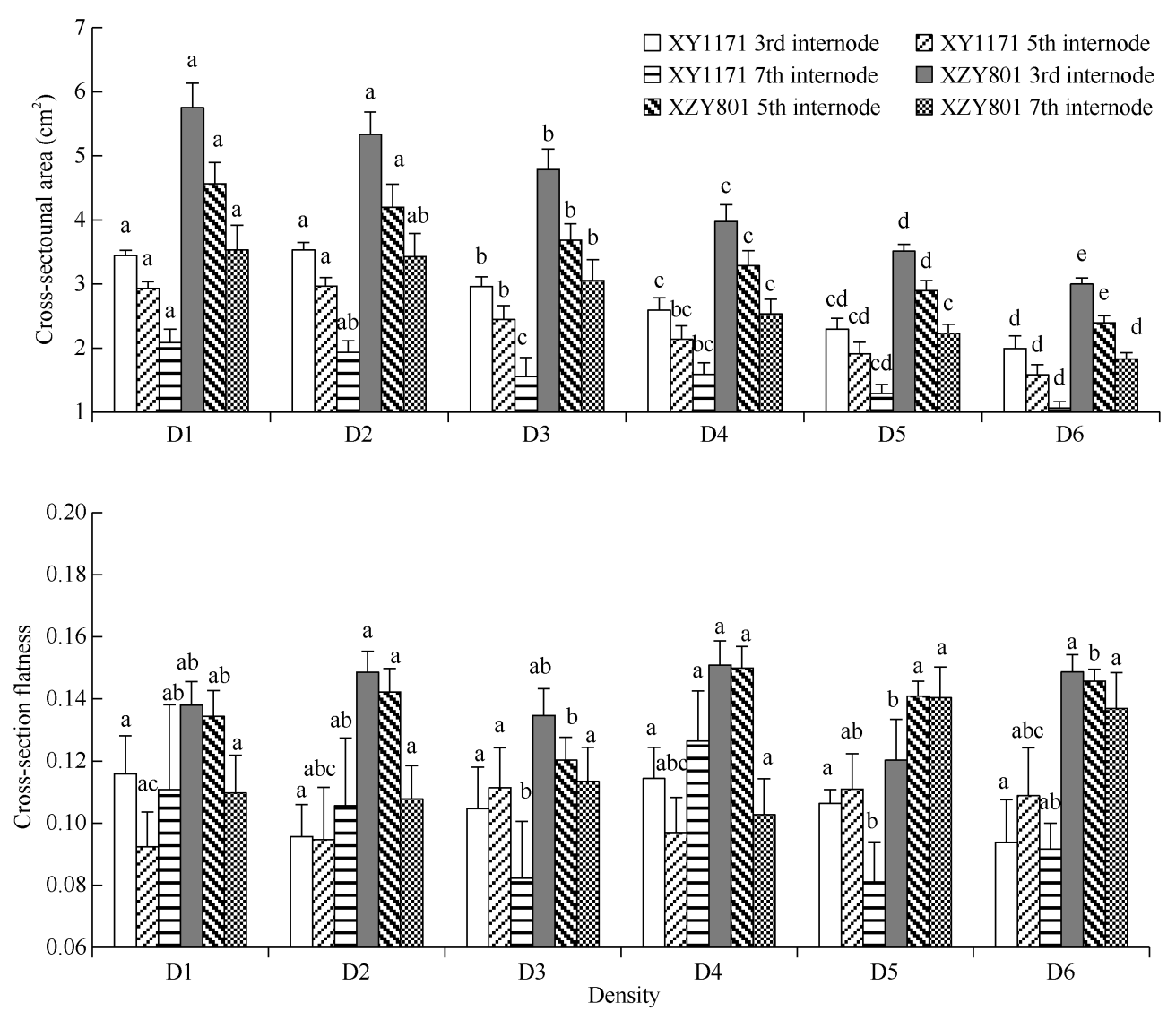

图 2 密度对玉米茎秆节间横截面积和横截面扁率的影响(2019 年)

Fig. 2 Effects of density on the cross-sectional area and cross-section flatness of maize stalk internodes in 2019

柱上不同小写字母表示处理间差异显著 $(P<0.05)$ 。D1、D2、D3、D4、D5 和 D6 分别代表种植密度 $3.0 \times 10^{4} 、 4.5 \times 10^{4} 、 6.0 \times 10^{4} 、 7.5 \times 10^{4} 、$ $9.0 \times 10^{4}$ 和 $10.5 \times 10^{4}$ 株 $\mathrm{hm}^{-2}$ 。XY1171: 先玉 $1171 ; \mathrm{XZY} 801$ : 新中玉 801 。

Bars marked with different lowercase letters indicate significantly different among treatments at $P<0.05$. D1, D2, D3, D4, D5, and D6 represent planting densities of $3.0 \times 10^{4}, 4.5 \times 10^{4}, 6.0 \times 10^{4}, 7.5 \times 10^{4}, 9.0 \times 10^{4}$, and $10.5 \times 10^{4}$ plants $\mathrm{hm}^{-2}$, respectively. XY1171: Xianyu 1171 ; XZY801: Xinzhongyu 801.

D1 密度相比, D2 D6 密度下茎秆第 3、5、7 节的穿 刺强度分别下降了 $7.02 \% \sim 22.98 \% 、 1.79 \% \sim 20.06 \%$ 和 $6.00 \% \sim 22.87 \%$; 抗折力分别下降了 $9.52 \% \sim 58.30 \%$ 、 $4.13 \% \sim 56.24 \%$ 和 $4.76 \% \sim 50.12 \%$, 可见密度对第 3 节 穿刺强度和抗折力影响最大。不同密度下, 先玉 1171 第 3 节穿刺强度变异系数较小, 第 $5 、 7$ 节的穿 刺强度变异系数和和抗折力变异系数较大, 可见先 玉 1171 第 3 节的穿刺强度对密度的响应较迟钝, 而 第 5、7 节的穿刺强度和茎秆抗折力对密度响应较敏 感。第 3 节的穿刺强度 2 年均值先玉 1171 比新中玉 801 极显著高出了 $9.33 \%$, 第 5、7 节品种间的差异 不显著; 第 3、5、7 节的平均抗折力比新中玉 801 极显著低了 $18.42 \% 、 34.14 \%$ 和 $35.62 \%$ 。2 018 年 2 品种第 5 节、第 7 节的穿刺强度均值显著低于 2019 年; 第 3、5、7 节的抗折力均值极显著高于 2019 年。 此外, 品种、年份互作、品种和密度互作显著影响 第 3 节抗折力; 密度和年份互作极显著影响第 3 节
抗折力。由此可见, 春玉米品种第 3 节的穿刺强度 在年际间相对稳定, 而第 3 节的抗折力受品种、密 度、年份及其相互作用共同影响。

2.4 种植密度对不同春玉米田间倒伏率和空秆 率的影响

由表 5 和图 4 可知, 春玉米倒伏率受品种、密 度、年份及其的相互关系共同影响, 密度和品种极 显著影响空秆率。随着密度的增加, 先玉 1171 的倒 伏率极显著高于新中玉 801 , 空秆率极显著低于新 中玉 801,2 年趋势相同, 2018 年 2 个品种倒伏率极 显著高于 2019 年。

\section{5 种植密度对春玉米产量及其构成的影响}

密度极显著影响春玉米产量(表 6 和表 7)。随密 度增加产量先上升后下降, 两者呈二次曲线关系。 通过回归方程求出先玉 1171 在密度为 9.3 万株 $\mathrm{hm}^{-2}$ 时产量最高, 达 $12,331.4 \mathrm{~kg} \mathrm{hm}^{-2}$; 新中玉 801 在密 度为 8.6 万株 $\mathrm{hm}^{-2}$ 时产量最高, 达 $11,063.6 \mathrm{~kg}$ 
$\mathrm{hm}^{-2}$ 。2 年平均产量先玉 $1171\left(10,847.8 \mathrm{~kg} \mathrm{hm}^{-2}\right)$ 比 新中玉 $801\left(10,158.0 \mathrm{~kg} \mathrm{hm}^{-2}\right)$ 高 $6.36 \%$, 高密度下比 新中玉 801 增产 $10.28 \%$, 差异达极显著水平，表明 增密后先玉 1171 增产幅度更大。

随着密度的增加, 有效穗数极显著增加, 穗粒数 和百粒重极显著降低, 但 2 个品种变化程度不同。密 度每增加 1.0 万株 $\mathrm{hm}^{-2}$, 先玉 1171 和新中玉 801 有效 穗数分别增加 7069.1 穗和 5448.1 穗, 穗粒数和百粒重
分别下降 14.2 粒、25.4 粒和 $0.7 \mathrm{~g} 、 0.8 \mathrm{~g}$ 。在高密度下, 先玉 1171 有效穗数、穗粒数 $(82,013.6$ 穗, 660.6 粒) 比 新中玉 801 (71,105.7 穗, 538.7 粒)显著高出 $13.30 \%$ 、 $18.45 \%$ ，而百粒重(30.3 g)显著低于新中玉 801 (34.6 g) $12.51 \%$ 。以上分析表明，在高度下先玉 1171 有效穗数 和穗粒数较多, 增密后有效穗数增加幅度较新中玉 801 高, 穗粒数和百粒重下降幅度较新中玉 801 低, 高 密度下趋于稳定, 因而能够获得高产。

表 4 不同春玉米茎秆穿刺强度、抗折力方差分析

Table 4 Variance analysis of puncture strength and bending resistance of different spring maize

\begin{tabular}{|c|c|c|c|c|c|c|}
\hline \multirow{2}{*}{$\begin{array}{c}\text { 变异来源 } \\
\text { Source of variation }\end{array}$} & \multicolumn{3}{|c|}{ 穿刺强度 Rind penetration strength } & \multicolumn{3}{|c|}{ 抗折力 Bending strength } \\
\hline & 3 & 5 & 7 & 3 & 5 & 7 \\
\hline 品种 Varieties (V) & ** & $\mathrm{ns}$ & $\mathrm{ns}$ & $* *$ & ** & ** \\
\hline 密度 Density (D) & $* *$ & $* *$ & $* *$ & $* *$ & $* *$ & ** \\
\hline 年份 Year (Y) & ns & $*$ & $* *$ & $* *$ & $* *$ & $* *$ \\
\hline 品种 $\times$ 密度 $V \times D$ & $\mathrm{~ns}$ & ns & ns & $*$ & $* *$ & $* *$ \\
\hline 品种 $\times$ 年份 $V \times Y$ & ns & $* *$ & $* *$ & $*$ & ns & ns \\
\hline 密度×年份 $\mathrm{D} \times \mathrm{Y}$ & ns & ns & ns & $* *$ & $* *$ & $* *$ \\
\hline
\end{tabular}

**表示在 $P<0.01$ 水平差异显著; *表示在 $P<0.05$ 水平差异显著; $\mathrm{ns}$ 表示差异不显著。

**: significantly different at $P<0.01 ; *$ : significantly different at $P<0.05$; ns: not significant differences.
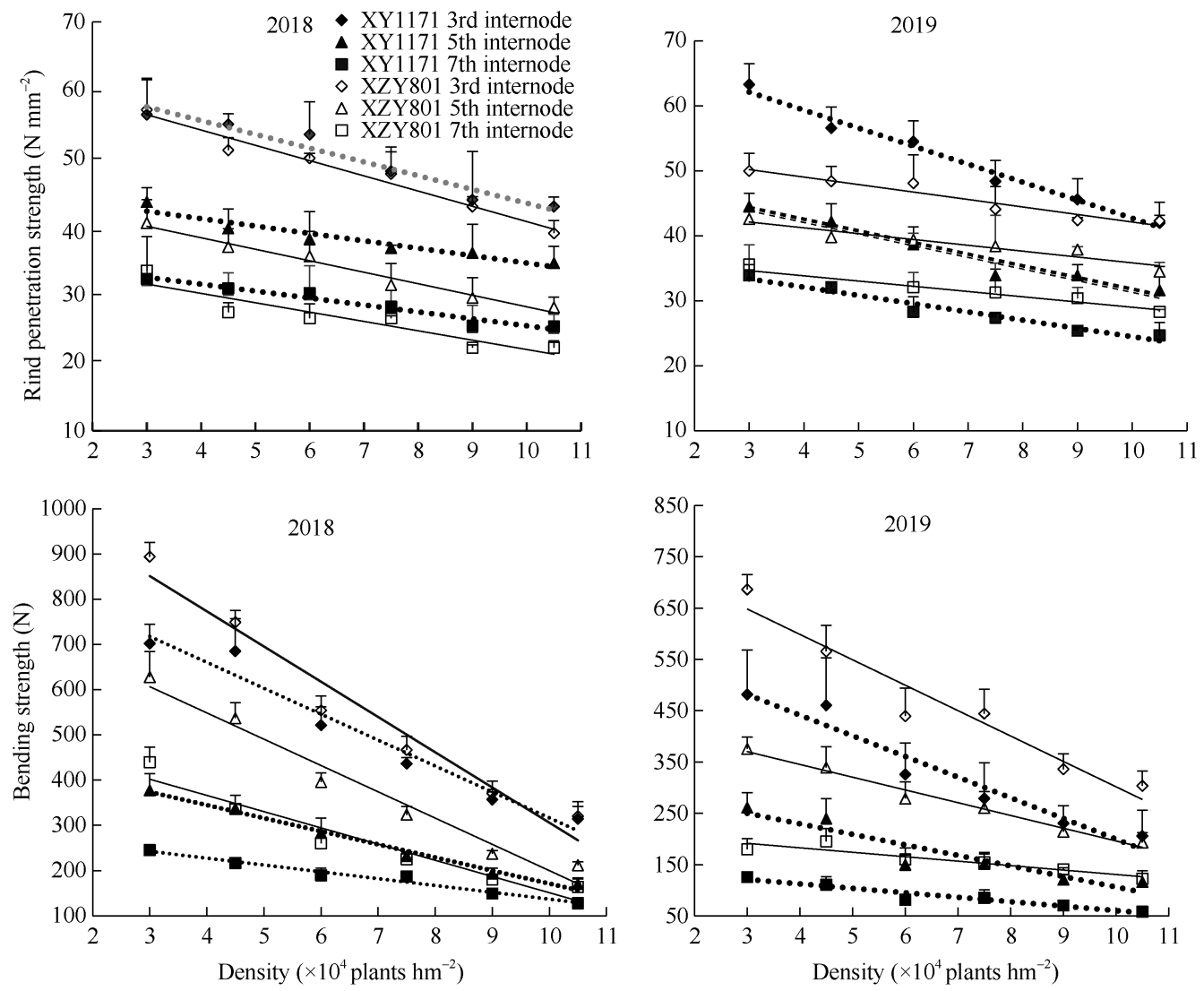

图 3 种植密度与茎秆穿刺强度、抗折力之间的关系

Fig. 3 Relationship between planting density and stalk puncture strength and bending resistance 缩写同图 2。Abbreviations are the same as those given in Fig. 2. 
表 5 不同春玉米品种倒伏率和空秆率方差分析

Table 5 Variance analysis of lodging rates and empty shot rate of different spring maize varieties

\begin{tabular}{lcc}
\hline $\begin{array}{c}\text { 变异来源 } \\
\text { Source of variation }\end{array}$ & $\begin{array}{c}\text { 倒伏率 } \\
\text { Lodging rate }\end{array}$ & $\begin{array}{c}\text { 空秆率 } \\
\text { Empty shot rate }\end{array}$ \\
\hline 品种 Varieties $(\mathrm{V})$ & $* *$ & $* *$ \\
密度 Density $(\mathrm{D})$ & $* *$ & $* *$ \\
年份 $\mathrm{Year}(\mathrm{Y})$ & $* *$ & $\mathrm{~ns}$ \\
品种×密度 $(\mathrm{V} \times \mathrm{D})$ & $*$ & $\mathrm{~ns}$ \\
品种×年份 $(\mathrm{V} \times \mathrm{Y})$ & $* *$ & $\mathrm{~ns}$ \\
密度 $\times$ 年份 $(\mathrm{D} \times \mathrm{Y})$ & $* *$ & $\mathrm{~ns}$ \\
**表示在 $P<0.01$ 水平差异显著; *表示在 $P<0.05$ 水平差异显著; \\
ns 表示差异不显著。 \\
$* *$ indicates significantly different at $P<0.01 ; *$ indicates signifi- \\
cantly different at $P<0.05$; ns: not significant differences.
\end{tabular}

2.6 茎秆形态、力学特性与倒伏率、产量之间的 关系

由表 8 可知, 倒伏率与株高、穗位高和节间长 呈极显著正相关，与节间粗、单位茎长干重、节间 横截面积、横截面扁率、穿刺强度极显著负相关, 与 抗折力显著负相关。其中与穗位高 $\left(0.88^{* *}\right)$ 相关性最 大。茎秆形态与力学特性的相关表现为抗折力与节 间长极显著负相关，穿刺强度、抗折力与节间粗、 节间干重、单位茎长干重和节间横截面积呈极显著 正相关，其中除节间干重外，抗折力与茎秆形态指 标的相关系数均大于穿刺强度, 说明抗折力与茎秆 形态指标的相关性更大, 能更好的反映春玉米的抗 倒伏性能。

产量与株高、穗位高、节间长呈极显著正相关， 与除横截面扁率的其他茎秆性状极显著负相关, 其 中与穗位高 $\left(0.77^{* *}\right)$ 正相关系数最大。可见, 玉米茎
秆性状与产量密切相关, 在高密植情况下, 春玉米 具有较高的穗位有利于群体获得高产, 协调高密条 件下群体产量与茎秆性状间的矛盾关系, 保障春玉 米密植高产抗倒的关键。

分别以倒伏率 $\left(Y_{1}\right)$ 和产量 $\left(Y_{2}\right)$ 为自变量, 以与其 显著相关的各项茎秆形态、力学指标为因变量, 进 行逐步回归分析, 得到最优回归方程。 $Y_{1}=$ $10.32+0.06 X_{1}-0.56 X_{9}\left(R^{2}=0.9520^{* *}\right)$ 。可见, 株高 $\left(X_{1}\right)$ 对倒伏率的正向影响最大, 穿刺强度 $\left(X_{9}\right)$ 对倒伏率 的负向影响最大, 二者之间对倒伏率的影响达极显 著水平。 $Y_{2}=7557.63+104.66 X_{3}-164.36 X_{9} \quad\left(R^{2}=\right.$ $\left.0.9247^{* *}\right)$ 。可见, 穗位高 $\left(X_{2}\right)$ 对产量的正向影响最大, 穿刺强度 $\left(X_{9}\right)$ 对产量的负向影响最大。以抗折力 $\left(Y_{3}\right)$ 为因变量, 以各茎秆形态指标为自变量, 进行逐步 回归分析, 得到最优回归方程。 $Y_{3}=-339.59+$ $28.03 X_{2}+301.30 X_{4}\left(R^{2}=0.9896^{* *}\right)$ 。可见, 节间粗 $\left(X_{2}\right)$ 和单位茎长干重 $\left(X_{4}\right)$ 对抗折力的正向影响较大, 可 作为评价玉米茎秆抗倒伏能力的重要指标。

\section{3 讨论}

种植密度显著影响玉米茎秆特性, 随密度增加, 玉米株高和穗位高先升高后降低 ${ }^{[16]}$, 穗位系数和节 间长逐渐增大 ${ }^{[20-21]}$ ，节间粗、节间干重和单位茎长 干重、茎秆力学强度显著降低 ${ }^{[22-23]}$ 。谷利敏等 ${ }^{[9]}$ 研 究发现增密后基部 3 7 节间增长、变细, 茎粗系数、 穿刺强度、抗折力、压碎强度显著降低。徐田军等 ${ }^{[24]}$ 研究认为随密度增大第 1 6 节茎秆增长, 第 $3 \sim 5$ 节 穿刺强度和抗折力逐渐下降, 不同节位第 3 节 $>$ 第 4 节>第 5 节。本研究结果表明, 增密后春玉米株高、 穗位高先升高后降低, 穗位系数逐渐增大; 第 3 节
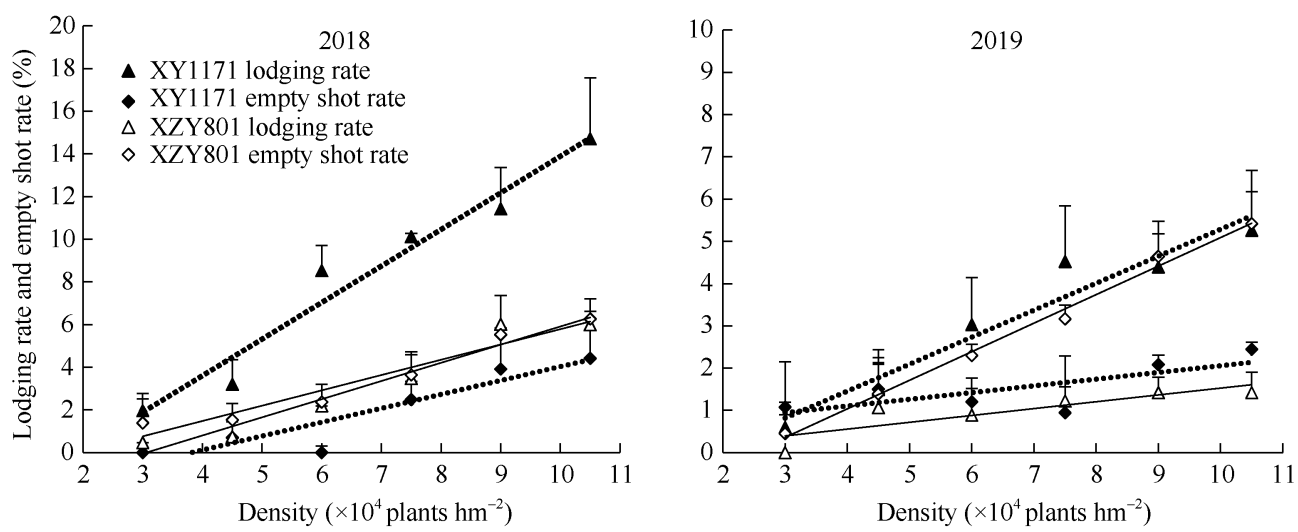

图 4 种植密度与倒伏率、空秆率的关系

Fig. 4 Relationship between planting density and lodging rate and empty shot rate 缩写同图 2。Abbreviations are the same as those given in Fig. 2. 
表 6 种植密度对不同春玉米产量及其构成的影响

Table 6 Effects of planting density on yield and composition of different spring maize

\begin{tabular}{|c|c|c|c|c|c|c|c|c|c|}
\hline \multirow[b]{2}{*}{$\begin{array}{c}\text { 品种 } \\
\text { Varieties }\end{array}$} & \multirow[b]{2}{*}{$\begin{array}{c}\text { 密度 } \\
\text { Density }\end{array}$} & \multicolumn{4}{|c|}{2018} & \multicolumn{4}{|c|}{2019} \\
\hline & & $\begin{array}{l}\text { 有效穗数 } \\
\text { Ear number }\end{array}$ & $\begin{array}{l}\text { 穗粒数 } \\
\text { Kernels } \\
\text { per ear }\end{array}$ & $\begin{array}{c}\text { 百粒重 } \\
\text { 100-kernel } \\
\text { weight (g) }\end{array}$ & $\begin{array}{c}\text { 籽粒产量 } \\
\text { Grain yield } \\
\left(\mathrm{kg} \mathrm{hm}^{-2}\right)\end{array}$ & $\begin{array}{l}\text { 有效穗数 } \\
\text { Ear number }\end{array}$ & $\begin{array}{l}\text { 穗粒数 } \\
\text { Kernels } \\
\text { per ear }\end{array}$ & $\begin{array}{c}\text { 百粒重 } \\
\text { 100-kernel } \\
\text { weight (g) }\end{array}$ & $\begin{array}{c}\text { 籽粒产量 } \\
\text { Grain yield } \\
\left(\mathrm{kg} \mathrm{hm}^{-2}\right)\end{array}$ \\
\hline \multirow{6}{*}{$\begin{array}{l}\text { 先玉 } 1171 \\
\text { Xianyu } 1171\end{array}$} & D1 & $45,959.6 \mathrm{~d}$ & $767.4 \mathrm{a}$ & $36.8 \mathrm{a}$ & $9145.3 \mathrm{~b}$ & $29,798.0 \mathrm{f}$ & $730.3 \mathrm{a}$ & $33.7 \mathrm{a}$ & $6345.4 \mathrm{~d}$ \\
\hline & D2 & $50,505.1 \mathrm{~d}$ & $754.4 \mathrm{a}$ & $36.4 \mathrm{a}$ & $10,232.1 \mathrm{~b}$ & $43,602.7 \mathrm{e}$ & $716.0 \mathrm{a}$ & $31.4 \mathrm{ab}$ & $9561.8 \mathrm{c}$ \\
\hline & D3 & $61,279.5 \mathrm{~d}$ & $749.1 \mathrm{a}$ & $33.8 \mathrm{~b}$ & $11,811.2 \mathrm{a}$ & $55,892.3 \mathrm{~d}$ & $685.6 \mathrm{ab}$ & $30.8 \mathrm{ab}$ & $10,350.4 \mathrm{~b}$ \\
\hline & D4 & $72,727.3 \mathrm{~b}$ & $653.8 \mathrm{~b}$ & $32.6 \mathrm{bc}$ & $11,891.7 \mathrm{a}$ & $70,033.7 \mathrm{c}$ & $658.3 \mathrm{~b}$ & $29.4 \mathrm{~b}$ & $11,609.4 \mathrm{a}$ \\
\hline & D5 & $76,936 \mathrm{~b}$ & $684.7 \mathrm{~b}$ & $33.2 \mathrm{bc}$ & $13,051.3 \mathrm{a}$ & $79,292.9 \mathrm{~b}$ & $637.9 \mathrm{~b}$ & $29.4 \mathrm{~b}$ & $11,858.6 \mathrm{a}$ \\
\hline & D6 & $87,878.8 \mathrm{a}$ & $677.0 \mathrm{~b}$ & $31.2 \mathrm{c}$ & $11,957.9 \mathrm{a}$ & $93,939.4 \mathrm{a}$ & $633.2 \mathrm{~b}$ & $29.0 \mathrm{~b}$ & $12,358.7 \mathrm{a}$ \\
\hline \multirow{6}{*}{$\begin{array}{l}\text { 新中玉 } 801 \\
\text { Xinzhongyu } \\
801\end{array}$} & D1 & $43,266.0 \mathrm{c}$ & $828.3 \mathrm{a}$ & $41.3 \mathrm{a}$ & $8177.7 \mathrm{c}$ & $37,037.0 \mathrm{f}$ & $669.1 \mathrm{a}$ & $36.6 \mathrm{a}$ & $8219.4 \mathrm{c}$ \\
\hline & D2 & $48,989.9 \mathrm{c}$ & $794.8 \mathrm{a}$ & $39.0 \mathrm{a}$ & $9046.9 \mathrm{bc}$ & $46,127.9 \mathrm{e}$ & $646.6 \mathrm{a}$ & $36.4 \mathrm{a}$ & $9629.5 \mathrm{~b}$ \\
\hline & D3 & $62,626.3 \mathrm{ab}$ & $633.3 \mathrm{~b}$ & $39.9 \mathrm{a}$ & $11,357.4 \mathrm{a}$ & $57,070.7 \mathrm{~d}$ & $627.1 \mathrm{a}$ & $36.3 \mathrm{a}$ & $10,744.7 \mathrm{a}$ \\
\hline & D4 & $61,784.5 \mathrm{~b}$ & $577.3 \mathrm{~b}$ & $36.1 \mathrm{~b}$ & $10,283.6 \mathrm{ab}$ & $67,340.1 \mathrm{c}$ & $566.2 \mathrm{~b}$ & $34.4 \mathrm{ab}$ & $10,744.6 \mathrm{a}$ \\
\hline & D5 & $66,330.0 \mathrm{ab}$ & $579.4 \mathrm{~b}$ & $35.6 \mathrm{~b}$ & $10,667.6 \mathrm{a}$ & $79,124.6 \mathrm{~b}$ & $511.4 \mathrm{c}$ & $33.6 \mathrm{ab}$ & $11,305.1 \mathrm{a}$ \\
\hline & D6 & $71,548.8 \mathrm{a}$ & $611.2 \mathrm{~b}$ & $34.1 \mathrm{~b}$ & $11,055.9 \mathrm{a}$ & $91,077.4 \mathrm{a}$ & $436.0 \mathrm{~d}$ & $32.6 \mathrm{~b}$ & $10,664.1 \mathrm{a}$ \\
\hline \multirow{6}{*}{$\begin{array}{l}\text { 变异来源 } \\
\text { Source of } \\
\text { variation }\end{array}$} & \multicolumn{2}{|c|}{ 品种 Varieties (V) } & \multicolumn{2}{|c|}{$*$} & $* *$ & \multicolumn{2}{|c|}{$* *$} & \multicolumn{2}{|c|}{$* *$} \\
\hline & \multicolumn{2}{|c|}{ 密度 Density (D) } & \multicolumn{2}{|c|}{$* *$} & $* *$ & \multicolumn{2}{|c|}{$* *$} & \multicolumn{2}{|c|}{$* *$} \\
\hline & \multicolumn{2}{|c|}{ 年份 Year (Y) } & \multicolumn{2}{|c|}{$\mathrm{ns}$} & $* *$ & \multicolumn{2}{|c|}{$* *$} & \multicolumn{2}{|c|}{$\mathrm{ns}$} \\
\hline & \multicolumn{2}{|c|}{ 品种×密度 $(\mathrm{V} \times \mathrm{D})$} & \multicolumn{2}{|c|}{ ns } & $*$ & \multicolumn{2}{|c|}{ ns } & \multicolumn{2}{|c|}{ ns } \\
\hline & \multicolumn{2}{|c|}{ 品种×年份 $(\mathrm{V} \times \mathrm{Y})$} & \multicolumn{2}{|c|}{$* *$} & $*$ & \multicolumn{2}{|c|}{$\mathrm{ns}$} & \multicolumn{2}{|r|}{$*$} \\
\hline & \multicolumn{2}{|c|}{ 密度×年份 $(\mathrm{D} \times \mathrm{Y})$} & \multicolumn{2}{|c|}{$* *$} & ns & \multicolumn{2}{|c|}{ ns } & \multicolumn{2}{|c|}{$\mathrm{ns}$} \\
\hline
\end{tabular}

处理同表 1 。同一列数字后不同小写字母表示不同处理间差异达 0.05 显著水平。**表示在 $P<0.01$ 水平差异显著; *表示在 $P<0.05$ 水平差异显著; $n s$ 表示差异不显著。

Treatments are the same as those given in Table 1. Values within a column followed by different lowercase letters are significantly different at the 0.05 probability level among different treatments. ${ }^{* *}$ : significantly different at $P<0.01$; *: significantly different at $P<0.05$; ns: not significant differences.

表 7 种植密度与春玉米产量及其构成因素回归关系

Table 7 Regression relationship between planting density and spring maize yield and its components

\begin{tabular}{|c|c|c|c|}
\hline $\begin{array}{l}\text { 项目 } \\
\text { Item }\end{array}$ & $\begin{array}{c}\text { 品种 } \\
\text { Varieties }\end{array}$ & $\begin{array}{c}\text { 回归方程 } \\
\text { Regression equation } \\
\end{array}$ & $R^{2}$ \\
\hline 产量 & 先玉 1171 Xianyu 1171 & $y=-112.4 x^{2}+2096.3 x+2555.5$ & $0.8331^{* *}$ \\
\hline Grain yield & 新中玉 801 Xinzhongyu 801 & $y=-89.6 x^{2}+1547.3 x+4385.2$ & $0.8589^{* *}$ \\
\hline 有效穗数 & 先玉 1171 Xianyu 1171 & $y=7069.1 x+16,271$ & $0.9955^{* *}$ \\
\hline Ear number & 新中玉 801 Xinzhongyu 801 & $y=5448.1 x+24,252$ & $0.9909^{* *}$ \\
\hline 穗粒数 & 先玉 1171 Xianyu 1171 & $y=-14.2 x+792.6$ & $0.9046^{* *}$ \\
\hline Kernels per ear & 新中玉 801 Xinzhongyu 801 & $y=-25.4 x+757.1$ & $0.8519^{* *}$ \\
\hline 百粒重 & 先玉 1171 Xianyu 1171 & $y=-0.7 x+36.8$ & $0.9227^{* *}$ \\
\hline 100-kernel weight & 新中玉 801 Xinzhongyu 801 & $y=-0.8 x+41.5$ & $0.9227^{* *}$ \\
\hline
\end{tabular}

${ }^{* *}$ 表示在 $P<0.01$ 水平上显著。 ${ }^{* *}:$ significant difference at $P<0.01$. 
表 8 茎秆形态、力学特性与倒伏率、产量之间的相关性分析

Table 8 Correlation analysis between stalk morphology, mechanical properties, lodging rate and yield

\begin{tabular}{|c|c|c|c|c|}
\hline $\begin{array}{l}\text { 指标 } \\
\text { Item }\end{array}$ & $\begin{array}{c}\text { 倒伏率 } \\
\text { Lodging rate }\end{array}$ & $\begin{array}{c}\text { 穿刺强度 } \\
\text { Rind penetration } \\
\text { strength }\end{array}$ & $\begin{array}{c}\text { 抗折力 } \\
\text { Bending strength }\end{array}$ & $\begin{array}{c}\text { 产量 } \\
\text { Grain yield }\end{array}$ \\
\hline 空秆率 Empty shot rate & -0.34 & $-0.51^{* *}$ & -0.29 & $-0.56^{* *}$ \\
\hline 株高 Plant height & $0.76^{* *}$ & -0.14 & -0.25 & $0.48^{*}$ \\
\hline 穗位高 Ear height & $0.88^{* *}$ & $-0.56^{* *}$ & -0.32 & $0.77^{* *}$ \\
\hline 穗位系数 Ear position coefficient & 0.01 & $-0.51^{* *}$ & -0.05 & 0.31 \\
\hline 节间长 Internode length & $0.75^{* *}$ & -0.39 & $-0.53^{* *}$ & $0.59^{* *}$ \\
\hline 节间粗 Internode stem thickness & $-0.54^{* *}$ & $0.64^{* *}$ & $0.88^{* *}$ & $-0.63^{* *}$ \\
\hline 节间干重 Internode dry weight & -0.34 & $0.82^{* *}$ & $0.76^{* *}$ & $-0.63^{* *}$ \\
\hline 单位茎长干重 Dry weight under length & $-0.60^{* *}$ & $0.81^{* *}$ & $0.83^{* *}$ & $-0.80^{* *}$ \\
\hline 节间横截面积 Cross-sectional area & $-0.82^{* *}$ & $0.49^{*}$ & $0.97^{* *}$ & $-0.52^{* *}$ \\
\hline 横截面扁率 Cross section flatness & $-0.59^{* *}$ & -0.08 & $0.47^{*}$ & -0.04 \\
\hline 穿刺强度 Rind penetration strength & $-0.55^{* *}$ & - & - & $-0.83^{* *}$ \\
\hline 抗折力 Bending strength & $-0.41^{*}$ & $0.61^{* *}$ & - & $-0.58^{* *}$ \\
\hline
\end{tabular}

“表示在 $P<0.01$ 水平上显著, "表示在 $P<0.05$ 水平上显著。

${ }^{* *}$ : significant difference at $P<0.01 ;^{*}$ : significant difference at $P<0.05$.

长增幅最大, 第3 3 节单位茎长干重、穿刺强度和抗折 力下降幅度最大; 第7节茎粗、干重和横截面积下降 幅度最大, 但密度对茎秆横截面扁率的影响不显 著。这表明密度增大后玉米群体对资源的竞争激烈, 植株个体发育变差, 茎秆细长, 导致玉米茎秆力学 特性显著下降。曹庆军 ${ }^{[25]}$ 研究认为株高、穗位高等 指标对密度的响应与不同品种抗倒性相关。勾玲等 [26]研究发现耐密抗倒品种穿刺强度随密度增加变异 幅度较小。邓妍等 ${ }^{[5]}$ 研究认为, 耐密品种茎秆性状、 抗倒力学性状对密度反应不敏感。本研究中 2 个品种 相比, 先玉1171株高对密度的响应较迟钝, 而穗位 系数对密度响应较敏感，原因在于新中玉 801 节间 长对密度的响应比先玉 1171 敏感, 随密度增加幅度 更快; 节间干重、单位茎长干重和第3节穿刺强度也 表现出先玉1171对密度的响应较迟缓, 但第5、7节 穿刺强度和茎秆抗折力对密度的响应较敏感。可见 不同品种茎秆形态和力学特性对密度的响应有所差 异, 茎秆形态和力学特性对密度的响应并不同步。 在评价品种耐密性和抗倒性时应选择对其影响最主 要的因素。此外, 本研究还发现, 年份也显著影响春 玉米株高、穗位高、节间粗、节间干重和抗折力，这 说明环境气候条件对春玉米的茎秆性状影响也较大, 在生产中应充分根据不同地区的气候差异进行合理 密植。

玉米茎秆形态、力学特性与茎秆抗倒性能具有
高度的相关性, 能够反映玉米品种抗倒伏能力的差 异 ${ }^{[27-29]}$ 。任佰朝等 ${ }^{[21]}$ 研究认为随密度增大, 茎秆穿 刺强度显著下降, 矮秆品种下降幅度较小能够保持 较好的抗倒伏能力。许荣荣等 ${ }^{[30}{ }^{30}$ 研究表明抗倒性强 的玉米品种具有茎秆较粗、株高和穗位高较矮、节 间长度较短等特点, 其中茎粗在不同抗倒性玉米品 种中差异显著。本研究中新中玉 801 两年平均株高、 穗位高、节间长显著低于先玉 1171 ，节间粗、单位 茎长干重、节间横截面积、横截面扁率和抗折力显 著高于先玉 1171, 因而增密后倒伏率显著低于先玉 1171 , 抗倒伏能力更强。 $\mathrm{Ma}$ 等 ${ }^{[23]}$ 指出倒伏率与穗位 高呈极显著正相关。马晓军等 ${ }^{[31]}$ 的研究表明, 倒伏 率与节间直径、干重、单位茎长干重, 第3 5 节穿刺 强度呈极显著负相关，与节间长度呈显著正相关。 刘晓林等 ${ }^{[32]}$ 研究表明茎秆抗倒力学特性与节间粗、 节间干重和单位茎长干重呈显著或极显著正相关, 而与株高、节间长和茎节长粗比呈负相关或极显著 负相关。本研究通过相关分析表明, 倒伏率与株高、 穗位高、节间长呈极显著正相关，与节间粗、单位 茎长干重、节间横截面积、横截面扁率、穿刺强度 极显著负相关, 与抗折力显著负相关, 其中与穗位 高 $\left(0.88^{* *}\right)$ 相关性最大, 说明先玉 1171 倒伏率高于新 中玉 801 是因为穗位更高。逐步分析表明, 株高是引 起倒伏的重要原因。此外, 抗折力与茎秆形态指标 的相关性更大, 节间粗和单位茎长干物质对抗折力 
的正向影响最大。这表明种植密度通过影响玉米茎 秆形态特性和干物质分配进而影响茎秆抗倒性能, 导致高密下玉米抗倒伏能力下降，株高、穗位高是 引起玉米茎秆抗倒伏能力变化的重要指标, 节间 粗、单位茎长干重可作为鉴定品种抗倒性差异的重 要指标。同时倒伏增大也会造成玉米减产, 产量损 失程度与倒伏发生程度及发生时期有很大关系, 开 花后至灌浆期这段时间发生倒伏对玉米产量的影响 较大 ${ }^{[33]}$ 。曹庆军 ${ }^{[25]}$ 研究表明, 倒伏率每增加 $1 \%$, 玉 米产量损失平均增加 $34.17 \mathrm{~kg} \mathrm{hm}^{-2}$ 。本研究中先玉 1171 在增密后其倒伏率显著高于新中玉 801 , 但是, 随着密度的增加, 增产幅度和产量都比新中玉 801 高。分析原因可能主要是在本试验条件下, 玉米灌 浆结实期均未发生倒伏，倒伏主要发生在结实后期, 因而对最终产量影响不大。新中玉 801 在增密后的空 秆率显著高于先玉 1171 , 使得高密度下有效穗数显 著低于先玉1171, 导致产量比先玉1171低。

增加种植密度是玉米增产的主要措施之一。玉 米要获得高产, 必须要构建合理的群体结构, 协调 产量构成因素间的矛盾 ${ }^{[34]}$ 。在适宜密度下, 增密能 提高单位面积穗数和籽粒产量, 当种植密度过大时 穗粒数和粒重的下降程度远大于单位面积穗数的增 加, 产量开始下降 ${ }^{[35]}$ 。柏延文等 ${ }^{[36]}$ 研究发现随密度 增加, 产量构成因素中穗粒数、百粒重下降幅度较 小的品种在高密度下产量更高。本研究中, 先玉 1171 比新中玉 801 更耐密高产, 高密度下比新中玉 801 增产 $10.28 \%$, 在高密下先玉 1171 有效穗数和穗 粒数显著高于新中玉 801 , 百粒重显著低于新中玉 801。这表明, 先玉 1171 密植高产的主要原因是增 密后有效穗数和穗粒数较大, 因而能够获得高产。 产量也与茎秆形态和力学特性密切相关 ${ }^{[29]}$ 。任佰朝 等 ${ }^{[21]}$ 研究认为, 矮秆品种随密度增加增产幅度更 高。刘晓林等 ${ }^{[32]}$ 研究认为, 单株产量与节间长和节 间长粗比呈显著负相关, 与节间粗、节间干重、单 位茎长干物质和茎秆穿刺强度呈显著正相关。本研 究发现，产量与株高、穗位高和节间长呈极显著正 相关，与节间粗、节间干重、单位茎长干物质、节 间横截面积、节间鲜密度、穿刺强度和抗折力极显 著负相关。这可能与本研究所选用的品种及生态条 件不同有关。

\section{4 结论}

不同春玉米茎秆抗倒伏性能和籽粒产量对密度
的响应不同。新中玉 801 增密后茎秆节间短而粗, 单 位茎长干重较大, 抗倒伏能力较强。而先玉 1171 由于在高密度下空秆率比新中玉 801 低, 有较高的 有效穗数和穗粒数, 因此高密度下籽粒产量更高。 综合考虑茎秆性状和产量, 先玉 1171 和新中玉 801 在贵州适宜密度分别为 9.0 万株 $\mathrm{hm}^{-2}$ 和 8.5 万株 $\mathrm{hm}^{-2}$ 。

\section{References}

[1] 李少昆, 赵久然, 董树亭, 赵明, 李潮海, 崔彦宏, 刘永红, 高 聚林, 薛吉全, 王立春, 王璞, 陆卫平, 王俊河, 杨祁峰, 王子 明. 中国玉米栽培研究进展与展望. 中国农业科学, 2017, 50: 1941-1959.

Li S K, Zhao J R, Dong S T, Zhao M, Li C H, Cui Y H, Liu Y H, Gao J L, Xue J Q, Wang L C, Wang P, Lu W P, Wang J H, Yang Q F, Wang Z M. Advances and prospects of maize cultivation in China. Sci Agric Sin, 2017, 50: 1941-1959 (in Chinese with English abstract).

[2] 明博, 谢瑞芝, 侯鹏, 李璐璐, 王克如, 李少昆. 2005-2016 年 中国玉米种植密度变化分析. 中国农业科学, 2017, 50: 1960-1972.

Ming B, Xie R Z, Hou P, Li L L, Wang K R, Li S K. Changes of maize planting density in China. Sci Agric Sin, 2017, 50: 1960-1972 (in Chinese with English abstract).

[3] 赵波, 李小龙, 周茂林, 宋碧, 雷恩, 李钟, 吴雅薇, 袁继超, 孔凡䂞. 西南玉米机械粒收籽粒破碎率现状及影响因素分析. 作物学报, 2020, 46: 74-83.

Zhao B, Li X L, Zhou M L, Song B, Lei E, Li Z, Wu Y W, Yuan J C, Kong F L. Current status and influencing factors of broken rate in mechanical grain harvesting of maize in Southwest China. Acta Agron Sin, 2020, 46: 74-83 (in Chinese with English abstract).

[4] 张琳琳, 孙仕军, 陈志君, 姜浩, 张旭东, 迟道才. 不同颜色 地膜与种植密度对春玉米干物质积累和产量的影响. 应用生 态学报, 2018, 29: 113-124.

Zhang L L, Sun S J, Chen Z J, Jiang H, Zhang X D, Chi D C. Effects of different colored plastic film mulching and planting density on dry matter accumulation and yield of spring maize. Chin J Appl Ecol, 2018, 29: 113-124 (in Chinese with English abstract).

[5] 邓妍, 王创云, 郭虹霞, 张丽光, 赵丽, 王陆军, 牛学谦, 王美 霞. 群体密度对玉米茎秆农艺性状、力学特性和产量的影响. 作物杂志, 2017, (4): 89-95.

Deng Y, Wang C Y, Guo H Y, Zhang L G, Zhao L, Wang L J, Niu $\mathrm{X}$ Q, Wang M X. Effect of population density on agronomic traits, mechanical properties and yield of maize stalks. Crops, 2017, (4): 89-95 (in Chinese with English abstract).

[6] 田再民, 黄智鸿, 陈建新, 史宝林, 魏东, 雗文洁, 李环. 种植 密度对 3 个紧凑型玉米品种抗倒伏性和产量的影响. 玉米科 学, 2016, 24(5): 83-88.

Tian Z M, Huang Z H, Chen J A, Shi B L, Wei D, Qu W J, Li H. Effects of planting density on lodging resistance and yield of three compact maize varieties. J Maize Sci, 2016, 24(5): 83-88 
(in Chinese with English abstract).

[7] 高釒金, 高聚林, 于晓芳, 王志刚, 孙继颖, 苏治军, 胡树平, 叶 君, 王海燕, 崔超, 李维敏. 高密植对不同类型玉米品种茎秆 抗倒特性及产量的影响. 玉米科学, 2012, 20(4): 69-73.

Gao X, Gao J L, Yu X F, Wang Z G, Sun J X, Su Z J, Hu S P, Ye J, Wang H Y, Cui C, Li W M. Stalks lodging-resistance characteristics and yield traits among different maize varieties under high close planting. J Maize Sci, 2012, 20(4): 69-73 (in Chinese with English abstract).

[8] 豆攀, 黄科程, 王兴龙, 马晓君, 张嘉莉, 孔凡磊, 袁继超. 川 中丘区不同玉米品种春、夏播茎秆抗倒特性研究. 华北农学报, 2017, 32(4): 162-168.

Dou P, Huang K C, Wang X L, Ma X J, Zhang J L, Kong F L, Yuan J C. Study on stalk lodging resistant of different maize varieties in spring and summer. Acta Agric Boreali-Sin, 2017, 32(4): 162-168 (in Chinese with English abstract).

[9] 谷利敏, 乔江方, 张美微, 朱卫红, 黄璐, 代书桃, 董树亭, 刘 京宝. 种植密度对不同耐密夏玉米品种茎秆性状与抗倒伏能 力的影响. 玉米科学, 2017, 25(5): 91-97.

Gu L M, Qiao J F, Zhang M W, Zhu W H, Huang L, Dai S T, Dong S T, Liu J B. Effect of planting density on stalk characteristics and lodging-resistant capacity of different density-resistant summer maize varieties. J Maize Sci, 2017, 25(5): 91-97 (in Chinese with English abstract).

[10] 勾玲, 黄建军, 张宾, 李涛, 孙锐, 赵明. 群体密度对玉米茎 秆抗倒力学和农艺性状的影响. 作物学报, 2007, 33: 1688-1695.

Gou L, Huang J J, Zhang B, Li T, Sun Y, Zhao M. Effects of population density on stalk lodging resistant mechanism and agronomic characteristics of maize. Acta Agron Sin, 2007, 33: 1688-1695 (in Chinese with English abstract).

[11] 刘胜群, 宋凤斌, 朱先灿, 张卫建, 任军, 宋振伟, 郭金瑞, 阎 孝贡. 玉米穗下节间与抗倒性相关的某些性状对增加密度的 响应. 土壤与作物, 2013, (4): 145-149.

Liu S Q, Song F B, Zhu X C, Zhang W J, Ren J, Song Z W, Guo J $\mathrm{R}$, Yan X G. Responses of internodes below ear and lodging-related traits to increased planting density in maize. Soil Crops, 2013, (4): 145-149 (in Chinese with English abstract).

[12] 马德志, 于乔乔, 孙玉珺, 吴玥, 张倩, 杨德光. 黑龙江省三、 四积温带玉米新品种抗倒伏性比较研究. 西南农业学报, 2019, 32: 1692-1700.

Ma D Z, Yu Q Q, Sun Y J, Wu Y, Zhang Q, Yang D G. Comparative study on lodging resistance of new maize varieties in three and four accumulated temperate zones in Heilongjiang province. Southwest China J Agric Sci, 2019, 32: 1692-1700 (in Chinese with English abstract).

[13] 尚常, 胡启国, 郭书亚, 张艳, 汤其宁, 卢广远. 种植密度对 黄淮海夏玉米品种倒伏率与茎秆抗倒特性的影响. 山西农业 科学, 2018, 46: 1282-1285.

Shang S, Hu Q G, Guo S Y, Zhang Y, Tang Q N, Lu G Y. Effect of planting density on lodging rate and stalk mechanics characteristic of summer maize varieties in the Huang-Huai-Hai region. $J$ Shanxi Agric Sci, 2018, 46: 1282-1285 (in Chinese with English abstract).

[14] 姚启伦. 玉米抗茎倒折性状遗传的研究. 西南农业大学学报, 2003, (2): 123-126.
Yao Q L. Studies of the inheritance of stalk breaking resistance traits in maize. J Southwest Agric Univ, 2013, (2): 123-126 (in Chinese with English abstract).

[15] 黄建军, 赵明, 刘娟, 不同抗倒能力玉米品种物质生产与分配 及产量性状研究. 玉米科学, 2009, 17(4): 82-88.

Huang J J, Zhao M, Liu J. Study on dry matter accumulation, distribution and yield traits of maize varieties differ in lodging resistant ability. J Maize Sci, 2009, 17(4): 82-88 (in Chinese with English abstract).

[16] 徐幸. 种植密度对不同株高玉米品种茎秆抗倒伏性能及产量 的影响. 吉林农业大学硕士学位论文, 吉林长春, 2019.

$\mathrm{Xu}$ X. The Effects of Planting Density on Stems Lodging Resistance and Yield for Different Plant Height Maize Varieties. MS Thesis of Jilin Agricultural University, Changchun, Jilin, China, 2019 (in Chinese with English abstract).

[17] 徐宗贵, 孙磊, 王浩, 王淑兰, 王小利, 李军. 种植密度对旱 地不同株型春玉米品种光合特性与产量的影响. 中国农业科 学, 2017, 50: 2463-2475.

Xu Z G, Sun L, Wang H, Wang S L, Wang X L, Li J. Effects of different planting densities on photosynthetic characteristics and yield of different variety types of spring maize on dryland. Sci Agric Sin, 2017, 50: 2463-2475 (in Chinese with English abstract).

[18] 金容, 李钟, 杨云, 周芳, 杜伦静, 李小龙, 孔凡否, 袁继超. 密度和株行距配置对川中丘区夏玉米群体光分布及雌雄穗分 化的影响. 作物学报, 2020, 46: 614-630.

Jin R, Li Z, Yang Y, Zhou F, Du L J, Li X L, Kong F L, Yuan J C. Effects of density and row spacing on population light distribution and male and female spike differentiation of summer maize in hilly area of central Sichuan. Acta Agron Sin, 2020, 46: 614-630 (in Chinese with English abstract).

[19] 张翼飞, 于崧, 杨克军, 徐晶宇, 吴琼, 王怀鹏, 尹雪巍, 杨丽. 不同氮钾配比对玉米茎秆形态力学特性及籽粒产量的影响. 生态学杂志, 2019, 38: 1741-1750.

Zhang Y F, Yu S, Yang K J, Xu J Y, Wu Q, Wang H P, Yin X W, Yang L. Effect of different nitrogen-potassium ratios on stem morphological and mechanical characteristics and grain yield of maize. Chin J Ecol, 2019, 38: 1741-1750 (in Chinese with English abstract).

[20] Yan P, Chen Y Q, Sui P, Alison V, Zhang X P. Effect of maize plant morphology on the formation of apical kernels at different sowing date sand under different plant densities. Field Crops Res, 2018, 223: 83-92.

[21] 任佰朝, 李利利, 董树亭, 刘鹏, 赵斌, 杨今胜, 王丁波, 张吉 旺. 种植密度对不同株高夏玉米品种茎秆性状与抗倒伏能力 的影响. 作物学报, 2016, 42: 1864-1872.

Ren B C, Li L L, Dong S T, Liu P, Zhao B, Yang J S, Wang D B, Zhang J W. Effects of plant density on stem traits and lodging resistance of summer maize hybrids with different plant heights. Acta Agron Sin, 2016, 42: 1864-1872 (in Chinese with English abstract).

[22] 蒋帆, 徐开未, 胡月秋, 龙玲, 周元, 莫太相, 钟贤华, 陈远学. 种植密度对川中丘陵春玉米茎秆性状及力学特性的影响. 云 南农业大学学报(自然科学), 2020, 35: 377-385.

Jiang F, Xu K W, Hu Y Q, Long L, Zhou Y, Mo T X, Zhong X H, Chen Y X. Effect of planting density on the stalk characteristics 
and mechanical properties of spring maize in hilly region of central Sichuan. J Yunnan Agric Univ (Nat Sci Edn), 2020, 35: 377-385 (in Chinese with English abstract).

[23] Ma D L, Xie R Z, Liu X, Niu X K, Hou P, Wang K R, Lu Y L, Li S K. Lodging-related stalk characteristics of maize varieties in China since the 1950s. Crop Sci, 2014, 54: 2805-2814.

[24] 徐田军, 吕天放, 陈传永, 刘月娥, 张译天, 刘秀芝, 赵久然, 王荣焕. 种植密度和植物生长调节剂对玉米茎秆性状的影响 及调控. 中国农业科学, 2019, 52: 629-638.

Xu T J, Lyu T F, Chen C Y, Liu Y E, Zhang Y T, Liu X Z, Zhao J $\mathrm{R}$, Wang R H. Effects of plant density and plant growth regulator on stalk traits of maize and their regulation. Sci Agric Sin, 2019, 52: 629-638 (in Chinese with English abstract).

[25] 曹庆军. 春玉米抗茎倒能力评价及其化学调控技术研究. 中 国科学院大学博士学位论文, 北京, 2016 .

Cao Q J. Evaluation of Stalk Lodging Resistance of Different Spring Maize Genotypes and Mechanism of Its Improvement by Plant Growth Regulators. PhD Dissertation of University of Chinese Academy of Sciences, Beijing, China, 2016 (in Chinese with English abstract).

[26] 勾玲, 黄建军, 孙锐, 丁在松, 董志强, 赵明. 玉米不同耐密 植品种茎秆穿刺强度的变化特征. 农业工程学报, 2010, 26(11): $156-162$.

Gou L, Huang J J, Sun R, Ding Z S, Dong Z Q, Zhao M. Variation characteristic of stalk penetration strength of maize with different density-tolerance varieties. Trans CSAE, 2010, 26(11): 156-162 (in Chinese with English abstract).

[27] 马延华, 孙德全, 李绥艳, 林红, 潘丽艳, 张长勇. 玉米茎皮 抗穿刺强度与形态性状和化学成分含量间的相关分析. 黑龙 江农业科学, 2012, (4): 1-4.

Ma Y H, Sun D Q, Li S Y, Lin H, Pan L Y, Zhang C Y. Correlation analysis between rind punctration resistance and morphological characters and chemical components in maize stalk. Heilongjiang Agric Sci, 2012, (4): 1-4 (in Chinese with English abstract)

[28] 丰光, 刘志芳, 李妍妍, 邢锦丰, 黄长玲. 玉米茎秆耐穿刺强 度的倒伏遗传研究. 作物学报, 2009, 35: 2133-2138.

Feng G, Liu Z F, Li Y Y, Xing J F, Huang C L. Genetics of lodging in tolerance to maize stem puncture. Acta Agron Sin, 2009, 35 : 2133-2138 (in Chinese with English abstract).

[29] 刘卫星, 王晨阳, 王强, 岳鹏莉, 谢旭东, 刘甘霖, 马耕, 卢红 芳. 不同玉米品种茎秆抗倒特性及其与产量的关系. 河南农 业科学, 2015, 44(7): 17-21.

Liu W X, Wang C Y, Wang Q, Yue P L, Xie X D, Liu G L, Ma G, Lu H F. Stalk lodging-resistance property and its correlation with yield among different maize varieties. Henan Agric Sci, 2015, 44(7): 17-21 (in Chinese with English abstract).
[30] 许荣荣, 马青美, 宋希云, 郭新梅, 裴玉贺. 不同玉米品种倒 伏抗性与产量相关性状的聚类和相关分析. 玉米科学, 2019, 27(5): 15-21.

Xu Y Y, Ma Q M, Song X Y, Guo X M, Pei Y H. Clustering and correlation analysis of lodging resistance and yield-related traits of different maize varieties. J Maize Sci, 2019, 27(5): 15-21 (in Chinese with English abstract).

[31] 马晓君, 路明远, 邢春景, 莫太相, 刘晓林, 吴雅薇, 袁继超, 孔凡否. 群体密度对夏玉米穗下茎秆性状及抗倒伏力学特性 的影响. 玉米科学, 2018, 26(4): 118-125.

Ma X J, Lu M Y, Xing C J, Mo T X, Liu X L, Wu Y W, Yuan J C, Kong $\mathrm{F}$ L. Effects of planting density on stalk and lodging-resistance in summer maize. J Maize Sci, 2018, 26(4): 118-125 (in Chinese with English abstract).

[32] 刘晓林, 马晓君, 豆攀, 黄科程, 王兴龙, 张頔, 孔凡否, 袁继 超. 种植密度对川中丘陵夏玉米茎秆性状及产量的影响. 中 国生态农业学报, 2017, 25: 356-364.

Liu X L, Ma X J, Dou P, Huang K C, Wang X L, Zhang F, Kong F L, Yuan J C. Effect of planting density on stem characteristics and yield of summer maize in the hilly central Sichuan basin. Chin J Eco-Agric, 2017, 25: 356-364 (in Chinese with English abstract).

[33] 曹铁华, 梁烜赫, 李刚, 任军, 王洪君, 陈宝玉, 王立春. 玉米 倒伏和扶直的产量效应研究. 玉米科学, 2013, 21(6): 81-83. Cao T H, Liang X H, Li G, Ren J, Wang H J, Chen B Y, Wang L C. Study on the yield effect of maize lodging and straightening. $J$ Maize Sci, 2013, 21(6): 81-83 (in Chinese with English abstract).

[34] 梁书荣, 赵会杰, 李洪岐, 王俊忠, 王林华, 曲小菲, 吕淑敏. 密度、种植方式和品种对夏玉米群体发育特征的影响. 生态学 报, 2010, 30: 1927-1931.

Liang S R, Zhao H J, Li H Q, Wang J Z, Wang L H, Qu X F, Lyu S M. Effects of density, planting methods and varieties on the developmental characteristics of summer maize populations. Acta Ecol Sin, 2010, 30: 1927-1931 (in Chinese with English abstract).

[35] Xu W J, Liu C W, Wang K R, Xie R Z, Ming B, Wang Y H, Zhang G Q, Liu G Z, Zhao R L, Fan P P, Li S K, Hou P. Adjusting maize plant density to different climatic conditions across a large longitudinal distance in China. Field Crops Res, 2017, 212: 126-134.

[36] 柏延文, 杨永红, 朱亚利, 李红杰, 薛吉全, 张仁和. 种植密 度对不同株型玉米冠层光能截获和产量的影响. 作物学报, 2019, 45: 1868-1879.

Bai Y W, Yang Y H, Zhu Y L, Li H J, Xue J Q, Zhang R H. Effect of planting density on light interception within canopy and grain yield of different plant types of maize. Acta Agron Sin, 2019, 45: 1868-1879 (in Chinese with English abstract). 